
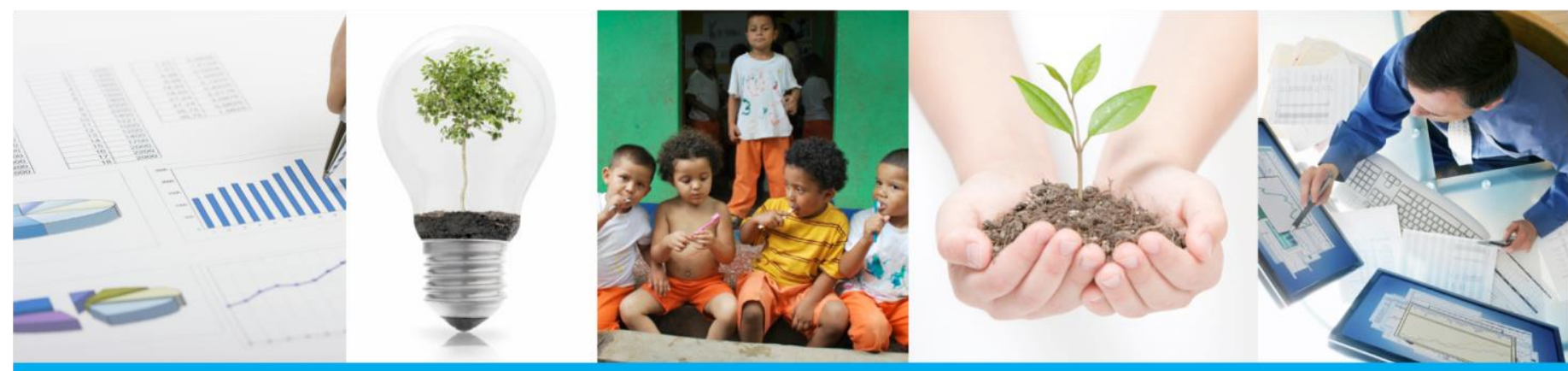

Obsessed with time?

White rabbit at CERN

Laia Pujol Priego

Jonathan Wareham 


\section{ESADE}

Ramon Lull University

\section{ESADE Working Papers Series}

Available from ESADE Knowledge

Web: www.esadeknowledge.com

\section{(c) ESADE}

Avda. Pedralbes, 60-62

E-08034 Barcelona

Tel.: +34 932806162

ISSN 2014-8135

Depósito Legal: B-4761-1992 


\title{
OBSESSED WITH TIME? WHITE RABBIT AT CERN
}

\author{
Laia Pujol \\ ESADE, Ramon Llull University, \\ laia.pujol@esade.edu \\ Jonathan Wareham \\ ESADE, Ramon Llull University, \\ jonathan.wareham@esade.edu
}

\begin{abstract}
To conduct research in fundamental science, big-science research infrastructures develop some of the most sophisticated technologies in existence. As such, mechanisms that can facilitate the transfer and commercialization of these technologies have vast potential to contribute to economic and social welfare. Scientists and engineers at CERN were confronted with the problem of minute data latency that was corrupting scientific measurements in their geographically distributed computing network. In response, they developed White Rabbit (WR) as open source hardware $(\mathrm{OSH})$. In a context of basic research and a deliberate decision to share the $\mathrm{R} \& \mathrm{D}$ process openly with no IP restrictions, WR is now commercialized in diverse economic sectors including finance, telecommunications, energy, Internet of Things (IoT), and air traffic control. We analyze the emergence, development, and exploitation of WR to a) identify the antecedents in which complex R\&D-intensive OSH differs from open source software (OSS), b) capture the mechanisms employed by CERN to stimulate firms' R\&D revelation and WR collaborative development, and c) investigate the business model configurations that companies have adopted in the commercial implementation of WR.
\end{abstract}

Keywords: Open source innovation, open source hardware, open business models, technology transfer. 


\section{INTRODUCTION}

"Oh dear! Oh dear! I shall be too late!" Alice follows him down the rabbit hole into Wonderland. The White Rabbit is the first Wonderland character Alice encounters in Alice's Adventures in Wonderland, a fantasy novel by English mathematician Charles Lutwidge Dodgson, published in 1865. White Rabbit (WR) is also the name of an open source hardware (henceforth OSH), which consists of a fully deterministic Ethernet-based network for data transfer and synchronization. The technology was initiated in 2008 by the European Organization for Nuclear Research (Centre européen pour la recherche nucléaire; henceforth CERN) to provide a sequencing and synchronization solution for CERN's accelerator network. WR was born as the evolution of the General Machine Timing (GMT) program, which is a clock and event distribution system for the existing accelerator timing systems. Specifically, engineers were trying to mitigate the problem of limited bandwidth and the impossibility of dynamically evaluating the delay induced by the data links that constitute CERN's geographically distributed computing infrastructure.

CERN is widely associated with the enlightenment-era ideal of the quest for pure scientific knowledge. However, as a byproduct, CERN, like other large-scale and capital-intensive research facilities defined as "big science" (Weinberg 1967), possesses a capacity to generate pioneering technologies by designing and building technical solutions to formidable and complex engineering problems. The tremendous potential of big-science centers to innovate has not gone unnoticed by policymakers who, after the "carte blanche" attitudes of early big-science endeavors (Autio et al. 2003), have increasingly demanded broader social value and greater return on investment via commercialization of their technologies. As a response, CERN established the Knowledge Transfer Group in 1997 to manage and advise on all activities related to technology transfer and intellectual property (IP) management. Yet, paradoxically, CERN, 
like its big-science comrades, has had to negotiate a tension between the goals of, on the one hand, greater openness and, on the other hand, generating revenue and economic stimulus via commercialized technology transfer.

The most famous and unprecedented case was the World Wide Web (specifically HTTP, URL, HTML) when Tim Berners-Lee convinced CERN's managers in 1993 to place it in the public domain and make the IP freely available to everyone. By accepting this, CERN effectively agreed not to draw revenues or economic value from it. As CERN IP management policy states: "In the case of a conflict between revenue generation and dissemination, openness takes precedence" (World Intellectual Property Organization 2010, p. 1).

CERN has continuously been a pioneer in opening up its inventions extensively using open source models for innovation. "Open Source" refers to the situation when an actor provides "access [to proprietary information] to all interested agents without the imposition of any direct payment" (Harhoff et al. 2003, p. 1754). Such a model is characterized by what West (2003) defined as an "essential tension" in information technology innovation between appropriating the returns from an innovation versus disseminating and gaining adoption of that innovation. It offers an alternative model to the private investment rationale of innovation, entailing the free revelation of inventions and knowledge that occurs without compensation guarantees. It renders valuable information a "public good," characterized by non-excludability and non-rivalry (Harhoff et al. 2003; von Hippel and von Krogh 2003; von Krogh and von Hippel 2006; Lakhani and von Hippel 2004; Lerner and Tirole 2003).

The open source model has been described by von Hippel and von Krogh (2003) as a privatecollective model of innovation. The private-collective modality occurs when public goods are produced through private contributions without any direct commercial compensation. The 
innovators that invest in the creation of the public good are compensated through a variety of intrinsic and extrinsic rewards that are realized through the process of creating this good; rewards that would typically not accrue to free riders. Free rider refers to the phenomenon whereby “someone profits from open source without reciprocating” (Ågerfalk et al. 2015, p. 4). From its inception to the present, this model has been applied to explain open source software development (henceforth OSS), where the focus has mainly been on individual contributors (Stuermer et al. 2009). However, little is known about how the model can be extended to the development of other technologies such as $\mathrm{OSH}$; and specifically, when actors involved in $\mathrm{OSH}$ development are profit-seeking firms. $\mathrm{OSH}$ is a term for hardware or tangible artifactsmachines, devices, or other physical things — whose design is made publicly available in such a way that anyone can study, modify, distribute, make and sell the design or hardware based on that design (OSH Association). Other terms used to refer to OSH include open design or open hardware design (West and Kuk 2014). OSH differs from OSS due to the nature of the design that requires building physical artifacts (West and Kuk 2014). Although the costs of reproducing software are negligible, hardware producers also need to manufacture the technology in the development and testing phases before having a final product for mass production. Pioneers in the field of OSH have acknowledged that "electrons are cheap, but atoms are expensive" (Ackerman 2008, p. 210).

Thus, the general question that remains is: How is it possible for CERN to open up and widely disseminate its technologies through free revelation as a public good, while simultaneously promoting the commercialization of complex and R\&D intensive hardware? When we refer to complex hardware, we refer to "a design state resulting from the multiplicity of, and relatedness among, product architectural elements" (Jacobs 2007, p. 7). Consequently, the research question we seek to answer is: 
How can a private-collective model of innovation function in OSH? What mechanisms motivate the contributions of for-profit firms?

We employ the term mechanism as in economics to refer to the compatibility of incentives towards desired objectives where participants act rationally (Hurwicz 1973).

To answer this question, we employ a longitudinal, inductive, case study approach, where we follow the emergence, development, and exploitation of WR initiated by CERN in 2008. This empirical setting allows us to contribute to open source innovation literature by extending the private-collective model (von Hippel and von Krogh 2003) to identify the antecedents in which OSH differs from traditional OSS, and implement an in-depth investigation of the mechanisms employed by CERN to stimulate firms' R\&D revelation and collaborative development for WR. We additionally contribute to OSH literature by shedding light on the business models adopted by companies over time to effectively capture economic value from WR.

The paper is structured as follows: First, we briefly review open source innovation literature. Next, we present the research design, followed by a WR case description. We then present our findings organized according to the mechanisms identified and the business model configurations that companies have adopted over time. This is followed by a discussion of the theoretical implications of our results and a conclusion about the implications for future research.

\section{THEORETICAL BACKGROUND}

Over the past 20 years, collaboration between firms, suppliers, and customers in the innovation process has led to diverse and partially overlapping theoretical approaches to reflect on how value is created and appropriated in an open and distributed innovation process (e.g., Chesbrough 2003, 2006; Henkel 2006). Some examples in the literature about such conceptualizations and frameworks include private-collective innovation (von Hippel and von Krogh 2003), distributed 
innovation (Lakhani and von Hippel 2004), commons-based peer production (Benkler 2006;

Ostrom 1990), the community-based model (Shah 2006), open sourcing (Ågerfalk and Fitzgerald 2008) and open innovation (Chesbrough 2003).

\section{The Private-Collective Model}

With the emergence and proliferation of OSS, von Hippel and von Krogh (2003) conceptualized the private-collective model of innovation to describe the situation where individuals or firms, considered economically rational actors, expend resources to generate innovations as "public goods." The model holds when innovators receive benefits from contributing to a public good that are greater than the associated costs, and that are not accessible to free riders or noncontributors (von Hippel and von Krogh 2003; von Krogh and von Hippel 2006).

\section{The private-collective model in OSS}

The private-collective model has been extensively applied in the literature to study OSS communities where the principal actors are individuals with no formal organizational affiliation—who “don't share a common employer and are not governed by an employment hierarchy" (West and O'Mahony 2008 p.2) - and freely reveal the source code that they create (e.g., Dedrick and West, 2003; Lakhani and von Hippel 2004; Lerner and Tirole 2003). Thorough examination has been carried out to assess the motivations of individual developers, which include: monetary benefits (Feller and Fitzgerald 2001; Lerner and Tirole 2003), reputation (Hann et al. 2004; West and Gallagher 2006), career prospects (Lerner and Tirole 2003), personal fulfilment (Torvalds and Diamond 2002), and learning a skill (Lakhani and von Hippel 2004), among others.

Research on the application of such a model for firm-level participation is less frequent (e.g., 
Dahlander and Wallin 2006; Henkel 2006; Jeppesen and Frederiksen 2006). Crowston et al. (2008) found that only $19 \%$ of publications that studied OSS did so using firm-level analysis. The main difference relies on the fact that individuals can have a variety of motivations for contributing to OSS development (i.e., various intrinsic and extrinsic motivations such as skill development, reputation, community benefits, or personal fulfillment). By contrast, the primary goal of companies is to profit from their investment.

Studies examining the motives of profit-seeking companies contributing to open source developments have highlighted similar motivations, such as: the ability to commercialize implementation and support services that leverage OSS expertise (e.g., Feller and Fitzgerald 2001; Lerner and Tirole 2003), greater insight into the capabilities and weaknesses of the core technologies (e.g., Fink 2003; von Hippel and Katz 2002; Lerner and Tirole 2003), promoting standardization (Fink 2003), and gaining social capital from direct interaction with other open source suppliers and users (Bonaccorsi and Rossi 2003). Here, companies can leverage the direct and indirect network effects that facilitate shared costs of development, testing and standardization, as well as a larger potential market of customers demanding implementation and support services along with related complements (Ågerfalk et al. 2015; Fink 2003; von Hippel and Katz 2002; Lerner and Tirole 2003).

\section{The private-collective model in $\mathrm{OSH}$}

The OSH concept has been modeled on OSS, from which it borrowed its principles, knowledge sharing dynamics, and hacking traditions (Oberloier and Pearce 2017). As a natural evolution of OSS, the rise of the do-it-yourself consumers (DIYers) and makers phenomenon has been nurtured by the growth of online platforms facilitating hardware design sharing, as well as a proliferation of physical maker spaces, hackspaces, FabLabs and other community workshops 
(Gibb 2014).

OSH is considered a relatively young phenomenon, emerging in the past decade (Balka et al. 2010; Bonvoisin et al. 2017), yet it has already produced concrete commercial implementations (Bonvoisin et al. 2017; Howard et al. 2012; Raasch and Herstatt 2011). Commercial examples of OSH include projects such as the electronic chip-card Arduino (arduino.cc); Local Motors (localmotors.com), a car that has been entirely registered under a Creative Commons license; RepRap (reprap.org), a self-replicable 3D printer; open source ecology (opensource-ecology.org); and a project developing forty machines for supporting a local community, among other examples (Boujut 2015). The Open Hardware Repository (ohwr.org; see Figure 1), one of the largest repositories today for electronics-focused OSH, included almost 300 projects at the time of writing (European Commission, 2019).

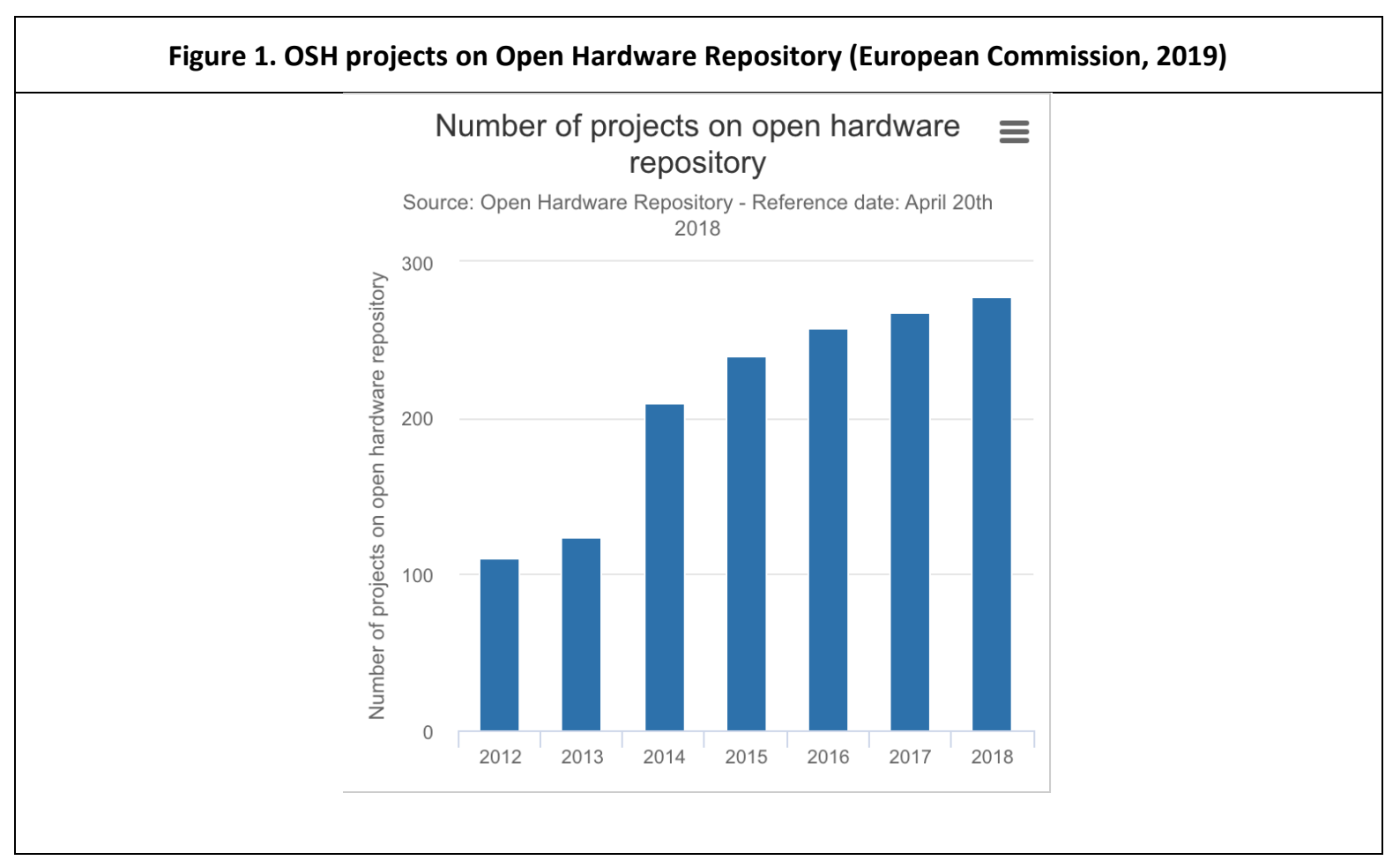

OSH projects share the common practice of publication of the design files and documentation regarding the physical artifact. Moreover, their development is governed through a license that allows any 
individual or organization to reproduce or modify the hardware, as well as to redistribute the design files so that others can improve, modify, add features, or fix bugs. In the case that OSH also contains OSS, then the software component is released under an open source license.

OSH is a rapidly evolving phenomenon with a diverse portfolio of types of collaboratively designed technologies such as computer systems and components, cameras, radio, telephony, scientific machines and tools, robotics, home automation, medical and biotech instruments, and automotive designs (Open Source Hardware Repository). Projects differ in terms of size and complexity; from a few individuals to several hundred accomplished developers along with technologyintensive private companies. They tackle hardware across all degrees of complexity and innovativeness, span various industries, and represent a full developmental spectrum from nascent ideas to mature, successfully marketed products (Balka et al. 2009).

We can distinguish two distinctive categories of $\mathrm{OSH}$ projects primarily according to product complexity and manufacturing strategy (Howard et al. 2012; Raasch et al. 2009): 1) DIY hardware, which refers to OSH products available to date, being gadgets for hobbyists or 3D printing designs shared by individuals on digital platforms such as Thingiverse $\mathrm{T}^{\mathrm{TM}}$ (Hansen and Howard 2013); and 2) OSH of complex products that require specialized development and industrial production. The first type refers to hardware that can be easily built and assembled by individual developers, typically with the support of 3D printing machines. In the second category, the high product complexity (Jacobs 2007) affects the process of development because the design, testing, and production require professional expertise in industrial production settings — calling for greater resources, sophisticated equipment, and facilities—with substantially longer development cycles (Rodriguez-Toro et al. 2004).

OSH success stories have attracted the attention of a wide range of organizations, including scientists searching for customizable scientific hardware to conduct experiments (e.g., Oberloier 
and Pearce 2017; Pearce 2012). This growing phenomenon has prompted some scholars to suggest a similar development path seen in OSS for OSH as it matures (Boujut 2015; Brynjolfsson 2014; Rifkin 2014). However, despite the initial success of the initial OSH efforts, very few have demonstrated the longevity and scale to sustain an economically vibrant ecosystem of contributors and complementors (Pearce 2017). Because of this, we have scant knowledge about how the privatecollective model extensively studied in OSS might apply to OSH and how the characteristics of a complex physical object might have different implications for the development process underlying the model (Raasch and Herstatt 2011). In particular, we lack a thorough understanding of the motives for for-profit firms to contribute to private-collective innovation in OSH requiring significant $R \& D$ investment, technical sophistication, and financially compensated labor (Raasch et al. 2009; West and Kuk 2014).

\section{Open Business Models}

Business models are described as “a mechanism that connects a firm's (innovative) technology to customer needs, and/or to other firm resources (e.g., technologies)" (Zott et al. 2011, p. 21). Firms commercialize their technological innovations through their business models to unlock the potential value embedded in such technologies and transform them into market outcomes (Amit and Zott 2001; Chesbrough 2007). Definitions of business models in the literature aggregate three major components (Fitzgerald 2006; Mahadevan 2000): value proposition for customers and vendors, how companies earn revenue, and the logistics component which is related to the organization of the supply chain.

Open source innovation requires that business models be able to capture value from openly shared or freely revealed technologies (Chesbrough 2007, 2010). Empirical studies on OSS have discussed the business strategies that commercial companies follow to capitalize on OSS 
initiatives, which basically consist of providing complementary services and products (e.g., Red Hat providing support for Linux-based products) and releasing existing company proprietary code under an open source license to boost its profit on a complementary segment (Fitzgerald 2006; Lerner and Tirole 2003). Those results are coherent with Teece (1986), who stressed the importance of different types of complementary assets that a company needs in order to succeed in the commercialization of a technological innovation, including "manufacturing, distribution, service, complementary technologies, brand and reputation" (Teece 1986, p. 289). Other scholars have highlighted the community benefits around the technology because it enables companies to extract continuous product improvements aligned with user needs, providing peer-to-peer support while attracting potential customers (Dahlander and Wallin 2006). The question that remains is how firms can manage to articulate business models capable of maximizing the value of their complementary assets while differentiating themselves from free riders. More concretely, despite the growing interest in the viability of $\mathrm{OSH}$, little is known about sustainable business model configurations based on OSH (Pearce 2017).

\section{METHOD}

\section{Overview of Research Approach}

Our research design has implemented a longitudinal, inductive, case study approach to be able to answer our "how" question in accordance with the exploratory nature of the study, and to capture the process of emergence, development and market exploitation of a complex hardware (Corbin and Strauss 1990; Pettigrew, 1990; Yin 2003). Our research consists of a single-case study focusing particular attention on sampling (Eisenhardt 1989). We selected the particular case of WR for three main reasons: fit, distinctiveness, and its revelatory nature (Siggelkow 2007; Yin 2003). First, the WR case serves to extend the private-collective model to other technologies 
beyond OSS, revealing how profit-seeking companies are motivated to expend a significant amount of economic resources on WR development while simultaneously sharing WR design information in the public domain. Second, the distinctiveness of the case is provided through its unique approach to producing a complex technology requiring industrial production and a significant R\&D investment in an open, collaborative model with extensive scale and sophistication. Third, we consider WR to be a revelatory case given the willingness of CERN and the WR community to divulge a variety of data—including documents, online exchanges, interviews, and study visits - which made it possible to answer the research question.

\section{Data Collection}

Our data collection focused on a diverse set of primary and secondary data. Primary data included 31 semi-structured interviews (see Table 1) and direct observations from two study visits at CERN conducted in 2017 and 2018, including participation in WR developer workshops. Interviews were chosen on the initial recommendation of the WR lead team at CERN, with subsequent recommendations from the interviewees. Our objective was to interview a representative cross section of the WR community. Secondary sources included information retrieved from the WR repository and Wiki, which contains: general information about the WR project (i.e. newsletters, list of companies involved in the WR ecosystem, descriptions of workshops organized, and a set of presentations and reports about WR), information about WR technology (i.e. synchronization, data delivery and standardization in IEEE1588-2008) and about the WR system (i.e. the switch, master and node), a full list of users of WR technology, and information about the open hardware license. We also gathered data from the websites of WR users and suppliers, research project websites that have integrated WR, social media information 
referring to WR (i.e., Twitter, blog posts), and additional journal articles identified not present in either the repository nor the Wiki.

\begin{tabular}{|c|c|c|c|}
\hline Type & Role & $\begin{array}{l}\text { № } \\
\text { Interviews }\end{array}$ & Identifiers \\
\hline \multirow{3}{*}{ 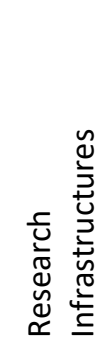 } & $\begin{array}{l}\text { Research scientists and engineers in research } \\
\text { infrastructures }\end{array}$ & 7 & $\begin{array}{l}\text { RSE1 ( } 2 \text { interviews); } \\
\text { RSE2 ( } 2 \text { interviews); } \\
\text { RSE3; RSE4; RSE 5; }\end{array}$ \\
\hline & $\begin{array}{l}\text { Officials at the technology transfer offices of research } \\
\text { infrastructures }\end{array}$ & 2 & RT1; RT2 \\
\hline & $\begin{array}{l}\text { Other staff in research infrastructures involved in WR } \\
\text { development }\end{array}$ & 5 & R1; R2; R3; R4; R5 \\
\hline \multirow{6}{*}{ 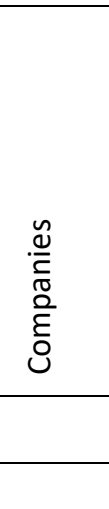 } & Companies developing software & 2 & $\mathrm{CS} 1 ; \mathrm{CS} 2$ \\
\hline & Companies developing hardware & 5 & $\begin{array}{l}\mathrm{CH} 1 \text { (2 interviews); } \\
\mathrm{CH} 2 ; \mathrm{CH} 3 ; \mathrm{CH} 4\end{array}$ \\
\hline & $\begin{array}{l}\text { Companies implementing pilots of WR with different } \\
\text { customers }\end{array}$ & 4 & CD1; CD2; CD3; CD4 \\
\hline & Customers of WR not involved in WR development & 5 & $\begin{array}{l}\text { CA1; CA2; CA3; CA4; } \\
\text { CA5 }\end{array}$ \\
\hline & Policy makers involved in technology transfer & 1 & P1 \\
\hline & Total & 31 & \\
\hline
\end{tabular}

The interview process was concluded when no significant additional insights were obtained from the data, and theoretical saturation was achieved.

\section{Data Analysis}

We performed a three-stage inductive analysis. The first stage was devoted to reading the abundant material available online about WR. We produced brief summaries that seek to go from technical descriptions to managerial inferences. Secondly, in-depth interviews were conducted to understand the characteristics of primary stakeholders involved in the WR community, their behaviors, and outcomes of their work. We further delineated the various goals of the actors and 
identified the main drivers, challenges, and overall mechanisms that enable WR development and adoption. The major themes in our interview protocol are summarized in Table 2.

\begin{tabular}{|c|c|}
\hline Themes & Description \\
\hline \multirow[t]{2}{*}{ Initial engagement } & How stakeholders know and initially get involved in WR \\
\hline & How they funded their investment for collaborating in WR \\
\hline Drivers & Main drivers for developing or adopting WR \\
\hline $\begin{array}{l}\text { Collaboration presence or } \\
\text { absence and dynamics }\end{array}$ & $\begin{array}{l}\text { The collaboration strategy that followed and how they contributed (or not) to the } \\
\text { WR community }\end{array}$ \\
\hline $\begin{array}{l}\text { Motivational aspects of } \\
\text { collaboration }\end{array}$ & $\begin{array}{l}\text { Motivational aspects behind the collaboration (e.g., reputational motivation, } \\
\text { monetary incentives, others) }\end{array}$ \\
\hline $\begin{array}{l}\text { Prospective business } \\
\text { model }\end{array}$ & Business models foresaw when collaborating or adopting WR \\
\hline Actual business model & Rationale and characteristics of business model implemented \\
\hline Scale-up strategies & Strategies to scale up the WR market and impact of standardization \\
\hline $\begin{array}{l}\text { Benefits and challenges of } \\
\text { open source approach in } \\
\text { WR }\end{array}$ & $\begin{array}{l}\text { Understanding the differences between using an open source versus a } \\
\text { proprietary hardware approach: impact on workload, costs and innovation cycle. }\end{array}$ \\
\hline Legal framework & The legal framework that enabled the collaboration \\
\hline WR technology & General thoughts about WR and its critical ingredients for uptake \\
\hline
\end{tabular}

We iteratively analyzed the interview transcripts, coding relevant observations and contrasting them with our analysis of secondary sources. We generated research memos that synthesize the emergent themes identified in the analysis and compared them with prior research. Finally, we confronted the empirical data with theory.

To validate our findings, we applied respondent validation (Maxwell 2013) by sharing our initial findings with the participants of the study and the WR community. The preliminary results were presented in a WR workshop on the 6th and 7th of October $2018^{1}$ to an audience of 56

${ }^{1}$ Workshop information published in https://www.ohwr.org/projects/5/wiki/oct2018meeting 
participants of the WR community, from whom we sought to gather feedback about the main results of the study. Additionally, a draft was shared with the interviewees to solicit their feedback.

Finally, we triangulated the results with a text-mining analysis performed by an independent researcher from CERN in October 2018 on the WR Repository where WR exchanges and information have been stored. We selected the analysis related to "Git logs" under "history," which provided us access to information such as: number of contributors, number of contributions (individual "commits" in terms of lines of code), organization (according to the affiliation of the author of the individual commitment), country, plus the aggregate of the percentage of contributions to be found in each organization. The results of such complementary analysis supporting our findings are provided in the Appendix.

\section{WHITE RABBIT}

Since the 1970s, particle physicists have used the so-called Standard Model to describe the fundamental structure of matter. CERN's researchers have deployed the world's most powerful particle accelerators and detectors to test the predictions and limits of the Standard Model, most recently, corroborating the existence of the Higgs boson.

WR was initiated in 2008 when engineers at CERN were confronted with limited bandwidth and the impossibility of dynamically evaluating the delay induced by the data links that constitute CERN's geographically distributed computing infrastructure. WR was conceived as the evolution of the General Machine Timing (GMT) program, developed with unprecedented specifications: a) transfer of a time reference from a central location to many destinations with an accuracy better than 1 nanosecond and a precision better than 50 picoseconds, b) ability to 
service more than 1,000 nodes, c) ability to cover distances of the order of $10 \mathrm{~km}$, and d) data transfer from a central controller to many nodes with a guaranteed upper bound in latency.

Two years later, WR was launched as a switched Ethernet network in which nodes automatically receive sub-nanosecond synchronization. The most precise standard synchronization method for Ethernet networks is the Precise Time Protocol (PTP), standardized as IEEE 1588. WR extends PTP in a backwardly compatible way to achieve sub-nanosecond accuracy (Moreira et al. 2009). WR switches permit users to set up highly deterministic data networks, thanks to having various internal queues for Ethernet frames of different priorities, as established by the priority header set in IEEE 802.1.Q (Figure 2). "The combination of deterministic latencies with a common notion of time to within one nanosecond allows WR to be a suitable technology to solve diverse problems in distributed real-time control and data acquisition" (Lipiński et al. 2011, p. 2).

The project started with the collaboration of CERN and GSI Helmholtzzentrum für Schwerionenforschung, a large-scale accelerator facility in Germany, together with two Spanish companies that helped to develop the WR hardware and software development. Motivated by the purposive engagement of CERN, a larger group of companies joined, progressively shaping a diverse and vibrant ecosystem of organizations developing open hardware $(n=4)$; proprietary hardware $(\mathrm{n}=6)$; software $(\mathrm{n}=1)$; firmware $(\mathrm{n}=1)$; and others developing long-distance WR (> $100 \mathrm{~km})(\mathrm{n}=1)$. 


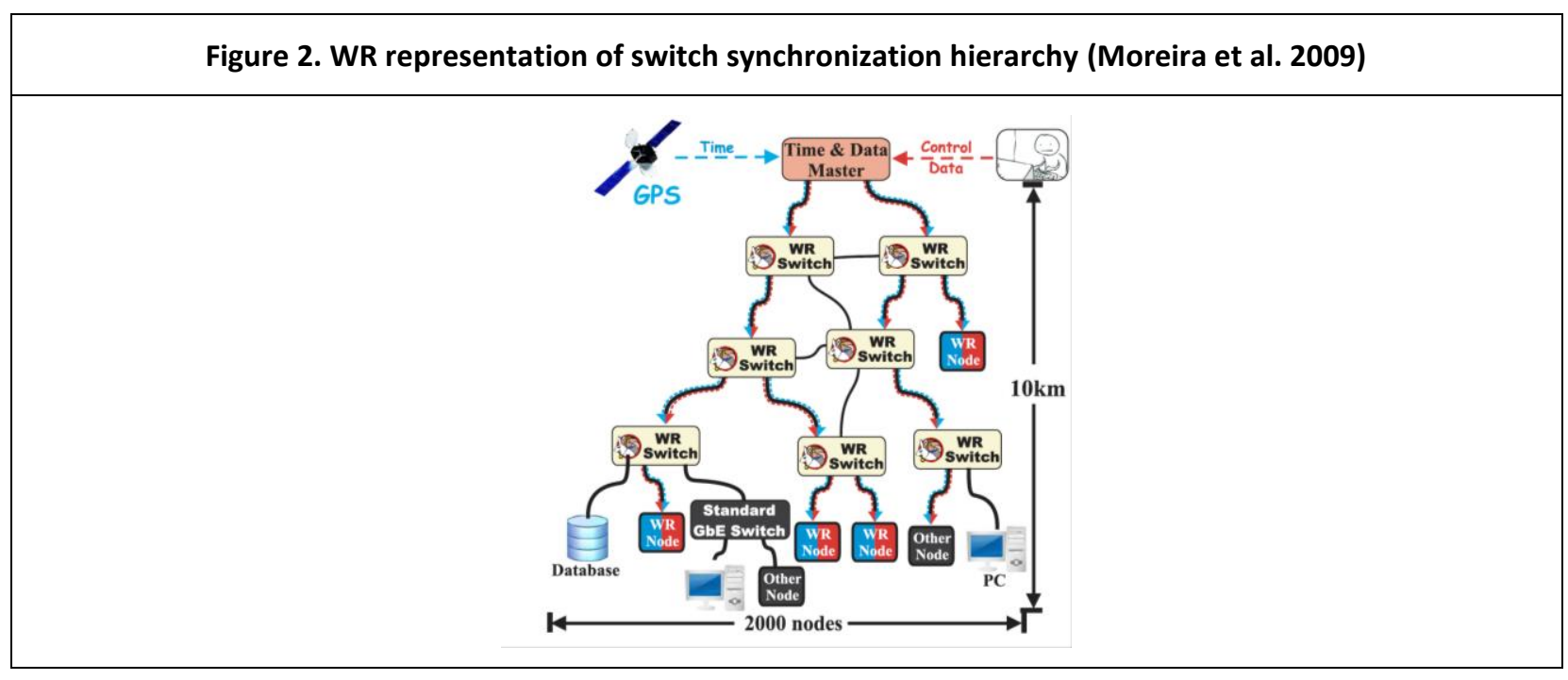

Applications of White Rabbit Technology

The first adopters of WR technology came from the scientific industry itself; that is, other largescale scientific facilities which constitute a sizeable market in their own right. At present, 30 scientific organizations have implemented WR, and 15 others are currently evaluating the technology, with a geographic scope that includes more than 20 countries around the world (according to the latest update in the White Rabbit repository). Some extraordinary examples include metrology research institutes that need to transfer time from atomic clocks over distances up to $1,000 \mathrm{~km}$; the neutrino telescope KM3Net located in the deepest seas of the Mediterranean; and a Cherenkov submarine detector with an instrumented volume of five cubic kilometers distributed between Toulon (France), Sicily (Italy) and Peloponnese (Greece). At the Large High Altitude Air Shower Observatory (LHAASO), China has invested 1.2 billion yuan (about US\$177 million) to build the world's largest and most sensitive cosmic-ray observatory (a 136hectare telescope array) for gamma-ray astronomy consisting of more than 6,300 detectors, 12 telescopes, and a central facility integrated by a detector-filled lightless water tank 2.5 times the size of Bejing's National Aquatics Center, located at the very high altitude of 4,410 meters above sea level. 
As Cao Zhen, the project's chief scientist claims: "Ultrahigh-energy particles could be the remnants and messengers of major cosmic events that could have happened billions of years ago in distant galaxies. When a high-energy particle enters the atmosphere, it ionizes (sheds one or more electrons) and charges the molecules in the air. The ionized molecules continue to bump into other molecules. After a dozen rounds, this creates a shower of secondary molecules spreading across a large area. The LHAASO will catch parts of the shower within nanoseconds, analyze their data, and find the one particle that started it all" (Zihao, 2017, p. 1). In order to reconstruct the air shower events, timestamps of all detector electronics and digitizers must be aligned better than 500 ps RMS. The synchronization of analog-to-digital converters requires $<100$ ps skew, which needs to be implemented in a remote environment with significant and rapid temperature variations ( -10 to +55 degrees Celsius). Such synchronization will be done using WR, which will consist of a final deployment of 564 WR switches and four layers connecting 6734 WR nodes embedded in each detector (Van Der Bij 2018). In a second stage, WR was adopted in different industrial settings, being commercialized in telecommunications, financial services, smart grids, air traffic control, the electronics and industry 4.0 applications. Examples include Vodafone, which conducted a successful proof of concept in 2017 in the Netherlands with the collaboration of the first worldwide supplier of short- and long-haul timing solutions based on WR Ethernet; and a company working in fiber optic networks to distribute accurate timing through the live Vodafone network. Within the proof of concept, time was measured with a surprisingly small error of less than one nanosecond over a cascade of four sites, spanning a total distance of $320 \mathrm{~km}$. This was considered the world's first successful deployment of WR in the production network of a commercial telecom operator. In financial services, High-Frequency Trading (HFT) matching engines are based on sequence needed to understand order-of-trade execution. A new regulation at the European level (i.e., 
MiFID II, adopted in June 2014) seeks to strengthen investor protection and improve the efficiency and transparency of financial markets. "Financial transaction organizations are required by law to prove that the time reference used for stamping transactions is UTC (Coordinated Universal Time) traceable. Thus, the accuracy required is in the millisecond range, but WR allows the nanosecond range with high accuracy, allowing legal timestamping applications" (CH1). "The financial industry has easily become the most obsessed with time," claims Balaji Prabhakar, a Stanford University electrical engineer (Markoff 2018). The Frankfurt Stock Exchange, one of the largest regional securities exchanges in Germany, operated by Deutsche Borse Group, contacted GSI to implement WR because it needed a time synchronization technology superior to the standard NTP and PTP. Deutsche Borse Group operates two electronic financial markets: Xetra, which is the leading market for exchange trading in Germany; and Eurex, a global reference derivatives exchange trading.

In Spain, the Madrid Stock Exchange (Bolsa de Madrid) is presently implementing a pilot for deploying WR with one supplier and an intermediary company with expertise in developing and operating the Galileo Time Validation Facility (TVF). The pilot consists in the development of a robust and accurate time distribution service via optical fiber over the Madrid region (in $44 \mathrm{~km}$ ), and traceable to UTC(ROA), the Spanish legal time.

In 2016, WR technology also attracted the attention of the Smart Grid application community. According to WR suppliers, power distribution measuring devices depend upon reliable synchronization being distributed across geographic areas, thus requiring accuracy in the microsecond range, especially for Phasor Measurement Units and Wide Area Measurement Systems.

In the case of air traffic control, a lack of accurate synchronization is a big concern. Modern central navigation systems use clusters operating in UTC domain and require high 
synchronization accuracy. For instance, for an airplane flying at about $1,000 \mathrm{~km} / \mathrm{h}$, the error of synchronization of a single second defines a position error of 300 meters. Voice control systems (VCS) require trusted timestamping to store pilot voice and telemetry flight data proving event chronology and non-repudiation where UTC leap second support is essential (Widomski et al. 2018). WR is currently being tested as a business application in various air traffic control regimes.

Automated vehicles are another major application of WR. Real-time control systems need explicit synchronization to enable applications such as automated driving where vehicles need to communicate with each other on the road. To do so, National Instruments (NI) approached CERN to integrate WR in their long-term strategy to improve the ability of distributed systems to support real-time control. As David Fuller, Vice President of Application and Embedded Software at NI, explains: "cyber-physical systems built from distributed compute nodes have to have a common notion of time. You have to have some standardized mechanism, so everything is on the same watch. The power of those things to do control comes down to the timescales that you can achieve in IoT. The less refined and accurate timing is, the less you can do" (Edwards 2014, p. 1). As Fuller adds: "To do more advanced things you need a more sophisticated notion of time. We need to allow for globally defined standards of the time. So this needs to be adopted in the core communications technologies. IoT systems will have to have the first-class notion of time for electronics and software."

Finally, WR has a potential market in any business setting where time accuracy is a critical issue and where synchronization can be responsible for system failures that can cost considerable amounts of money or lives. 


\section{RESULTS}

The most significant decision that CERN made concerning WR is to develop it in an open source regime. This had several benefits. First, an open source approach made it possible to avoid a vendor lock-in situation; given the initially high asset-specificity of the technology, there is a high risk of dependency on specific technology suppliers. Secondly, an open source model should offer a more diverse and rigorous evaluation of technology development. As RSE 1 reveals: "By sharing designs openly, CERN was seeking to improve the design quality through peer review and to reduce duplication of efforts." Finally, flexibility is a particularly important characteristic for researchers working on the edge of science who need customized, neverbefore-seen equipment to meet their exact needs and specifications in an uncertain and modular environment (Pearce 2014). RSE4 summarizes these concerns: "We chose an OSH approach because we wanted to get a design just the way we want it. We wanted to specify the design fully. On the other side, through this approach, we could get our design reviewed by experts all around the world while avoiding vendor-locked situations. However, we had to select companies and convince them to help us. This opened the door to smaller companies with good local support."

The premise of our analysis is that a private-collective model emerges when there are adequate mechanisms to mitigate the costs and increase the benefits of OSH contributions. As such, we begin by delineating five mechanisms deployed to cultivate the development and supply of WR technologies (see summary in Table 3). Subsequently, we describe three modalities where firms managed to commercially exploit WR and stimulate its market adoption. 


\section{Stimulating Supply-5 Mechanisms}

\section{Mechanism 1: Sponsorship for first contributors}

One of the main challenges that CERN faced was to reduce the barriers for WR contributors, especially for first contributors. Being the first company to invest in the development of a complex technology such as WR requires a critical mass of companies with whom to share risks. The risk is higher for the first company to engage, less for the second, falling commensurately as additional companies join. In order to minimize the risk for the first contributors, CERN convinced the Spanish Ministry of Industry and Commerce to subsidize the first two organizations collaborating on the development of WR software and hardware. "We are a small company, and we could not have started alone developing WR without the support of some external funding" (CH2). As $\mathrm{CH} 2$ further describes: "When I do an overall evaluation of how much we have spent in WR development, I think that the initial subsidy was less than $50 \%$ of what we have invested, but we needed such financial support to start." In addition to the subsidy, in the initial years of technology development, CERN also compensated the work of companies through public procurement. This made a difference compared to other open source technologies developed at CERN: "We knew CERN was serious this time by engaging firms, and this also sent a message to other organizations that could collaborate with us" (CH2). As RSE1 explains: "After this first step, we were aware that we needed some redundancy in the system, so we needed to engage other companies that could also supply WR in the future, so we needed to do something else.” RSE4: "After allocating some funding for the first companies to join, we needed to convince others to invest in developing WR, which was not an easy task. I had to reach out proactively with the companies we knew could do it and convince them. We needed first to 
select companies that had not only the expertise but also the capacity afterward to provide support to WR product."

\section{Mechanism 2: Compromise between Open and Proprietary Hardware}

Full disclosure of R\&D process and product design challenges the suppliers' ability to differentiate. To succeed, WR tried to manage the highly heterogeneous drivers of commercial and noncommercial demands. This required that CERN and WR members tolerate some degree of cooperation and competition, allowing the development of proprietary technologies in parallel with the open source standards through a permissive license (Dahlander and Wallin 2006).

“After I started being involved with WR, soon another department of the company started to develop technologies around WR" (CD2). As CH4 describes: "My company wanted me to go and find out more about WR technology, so I attended to the first WR workshop, and that is when I learned that it was going to be open hardware based in GPL. However, my company had concerns, so I voiced back to the WR community our major problem: we wanted to ensure that we could help develop and use the components of WR without having to open up the rest of our design, as we wanted to develop our proprietary hardware based on WR. This was when CERN decided to create a new open hardware license scheme that ensured that we (and others) could use these components of WR without having to open up the rest of our designs." As CH4 further explains: "We have developed a lot of products and IP that we do not open to our competitors. Some of them we have patents, and we did not want to incorporate these into WR. With the earlier version of the license, we would need to open up our designs. But CERN changed the nature of the license, so we decided to engage and help in WR development."

This hybrid model of supporting the open source core technologies while permitting proprietary complements is consistent with practice in OSS (e.g., West and Gallagher 2006). This hybrid 
strategy helped offset the costs of the effort of companies contributing to WR open source development. As CH4 further reveals: "While we participated in WR workshops and developments, we took the concepts and principles of WR technology and developed our product. Since we understood the requirements, we did not take the IP directed from the repository, and we created our IP." On the other side, allowing the nondisclosure of improvements to WR design also implied breaking the principles of mutuality and reciprocity, allowing free riders to profit from the open source technology without the obligation to declare improvements (without reciprocating).

\section{Mechanism 3: "Grandfathering"}

Complex hardware development requires attracting strong technical capabilities. CERN actively engaged itself in an unprecedented manner with the companies (and future suppliers of WR) to provide them with both technical and managerial support. The underlying rationale was to return as many rewards and profits as possible back to WR contributors. As one company member puts it: "It took a lot of time and effort to develop WR. It took so many years, so many organizations and so much money to transform the product because WR is not simply a prototype that works in lab conditions, it is a real product that works under plenty of different conditions" (CH1). As RSE4 describes: "Additional effort is needed to make CERN designs a working product. This includes a particular effort to reduce the bill of material and precise production documentation, and a serious effort in testing.” Thus, CERN was obliged to guide companies in the technical development of WR as well as its preliminary commercialization. "CERN was our 'grandfather' —not only when we were developing WR together, but also in the first moments when we were wondering what was next; when we had to go to the outside world with WR together" (CH2). 
From a technical point of view, companies anticipated learning gains from close cooperation with CERN (Stuermer et al., 2009). Big-science infrastructures such as CERN offer unique opportunities for organizations to upgrade their skills base and extract learning gains from the collaboration (e.g., Allen 1983; Autio et al. 2003; Nuvolari 2004; West and Kuk 2014). CERN staff is accustomed to providing support to domestic companies bidding for big-science procurement projects (Autio 2014). "CERN has the capacity to attract talent to develop their technologies — and we knew that" (CD2). "To develop WR as open source would help us to get specialist knowledge, where we know that small companies play a large role, but on the other hand, we would need to support them and help them to achieve the quality we need. Companies benefit from that process because it helps them improve and produce better hardware" (RSE4). Moreover, as RSE4 further explains, companies were motivated to participate in the open collaboration because doing so would enable them to gain not only time but also, notably, quality: "it would help them find complex bugs that may have been discovered only much later."

\section{Mechanism 4: Branding and Reputation}

One of the main challenges for firms evaluating WR was the community's ability to reach first adopters and to stimulate the technology uptake. However, in the WR case, as CD1 reported: "The fact that CERN was part of WR development made us think that it would help us gain customers' confidence." "We knew we had the first customer with CERN" (CH2). As RSE4 explains: "Companies recognized that they got interesting contacts by collaborating with us."

Companies joining WR expected to be differentiated in the market from other suppliers for having the reputation of the first supplier of WR to CERN and GSI. Suppliers sought to capitalize on CERN and GSI branding with other research infrastructures. Not only did CERN and GSI provide "reputation" to WR suppliers, but they also facilitated access to industrial 
customers; CERN and GSI supported the companies engaged in WR development to succeed in the commercialization of the technology. As Bij et al. (2013) explained: “OSH also fits CERN's role of transferring the technologies it has developed to industry and to stimulate industry with innovative products such as the WR. In the process, we are even promoting new business models. Also, personally we find it very motivating to see our work reused in diverse areas such as trains in South Africa, telescopes in Siberia and China, and seeing our designs challenged by extending their use over distances of hundred times the original design goal or seeing our boards used under extreme temperature or high-voltage conditions." Although it was beyond the scope of tasks expected of a research infrastructure such as CERN or GSI, both organizations supported the suppliers' engagement in the community to develop new business models and access to potential customers to commercialize WR technologies. As customer CA1 explains: "Many thanks to GSI for giving us our first White Rabbit demonstration, which convinced us to contact the supplier that they suggested to us and deploy it in our organization."

\section{Mechanism 5: Standardization}

Despite strong reputational effects from CERN and GSI, companies expressed concerns about the stability of technology as complex as WR, as well as the capabilities and longevity of customers beyond CERN and GSI. CERN and the WR community determined that formulating standards around WR would be beneficial to establishing security in WR's technological evolution and facilitating WR awareness in a plurality of industries. As CH4 explains: "When I tried to talk with my company and tried to convince more and more people within the company about the possibility of engaging in WR technology development, they were worried about developing products for a technology that was not standardized, and that could change over time. This would be expensive for us because our products would not meet the new versions. So they 
wanted something that could be standardized. This is why I talked to CERN about this, voiced our concerns from the industry perspective, and when they got involved with IEEE 1588 . This is a common time synchronization standard, and they have been working incorporating WR since 2013." As CH2 reveals: "The standardization process was possible because it was open hardware. If it were a proprietary technology, it would have been simply impossible." "A standardization process for WR would be time consuming for us. We had to think about it, but it could only be positive" (RSE 1). Putting WR under such process was expected to increase the stability, viability, and credibility of the technology while fostering the feedback of experts and eventually fine-tuning the technology. As for the other open source cases, compatibility with other applications would be beneficial to increase WR adoption (Dedrick and West 2003). As Bij et al. (2013) revealed: "The WR timing and control network, although it looked at first rather specific, found a place in applications that we had not thought about before. Using standards for the bus type, mezzanine type and for the internals of the firmware help us to collaborate and does modules that are easier to reuse. We contributed novel work to extend existing standards to include requirements that were not yet available."

Different paths for WR standardization were assessed, and it resulted in the decision to make WR an extension of the IEEE1588-2008 standard. In mid-2013, the PTP revision process was carried out by the P1588 working group, which is composed of an estimated number of 180 members around the world representing the industry and scientific infrastructures. The standardization process is now in the final stage with the publication of the standard due in 2019. Once finished, the generalized WR (under the name High Accuracy) will be the third default PTP Profile included in Annex J of the IEEE1588. 


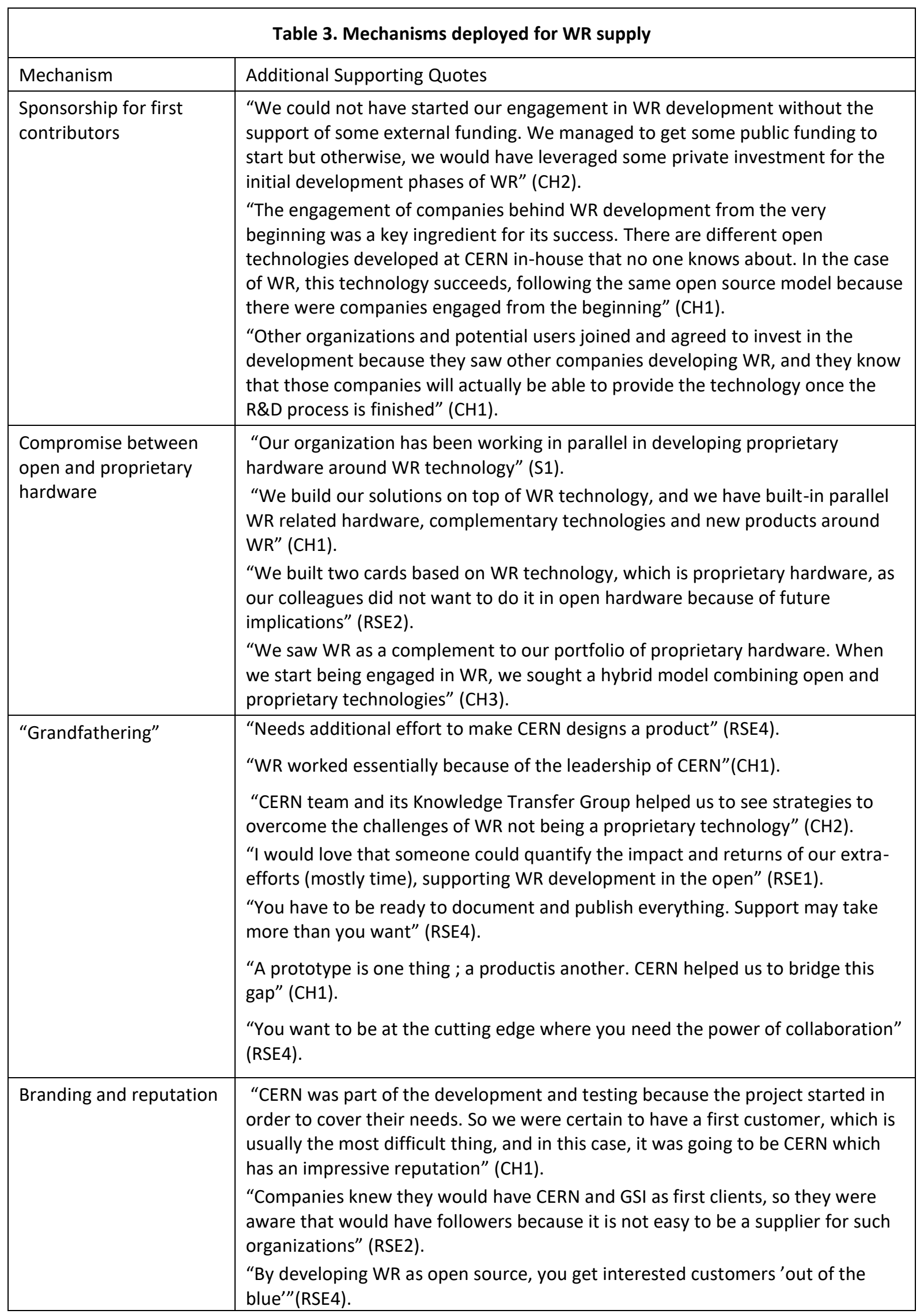




\begin{tabular}{|l|l|}
\hline Standardization & "People we did not reach, contacted us in order to supply them WR" (CH4). \\
& "The standardization process has increased awareness, not only for potential \\
users of WR technology but also amongst ourselves about the potential \\
application of such technology in diverse settings" (CD2). \\
"The variety of people involved in the working group makes you believe that the \\
potential of WR is still to be seen" (CD1). \\
"By using relevant standards, more people will already have knowledge of a part \\
of a design, facilitating understanding and adaptation. For example, we have \\
chosen PCI Express, a bus standard that can be found in any desktop personal \\
computer. Also, VME is a modular bus system that is common in the high-energy \\
physics world. For the mezzanine card concept, we used the FMC standard, \\
while for the internals of the programmable FPGA we use the open Wishbone \\
internal bus, OpenCores IP and plain VHDL code. Finally, as driver software, we \\
support the Linux operating system. In the cases where no standard could fulfill \\
our needs, we made our own developments that we subsequently contributed \\
to existing standards"(Bij et al. 2013, p. 5).
\end{tabular}

\section{Stimulating Demand: Three Business Models}

While CERN succeeds in extending the public-private collective model for WR supply, how did companies actually succeed in commercializing WR?

The traditional business model for most commercial hardware companies is based on keeping the details of the design secret (Pearce 2017). By doing this, they are able to maximize the margins. In the case of WR, under the conditions of a weak appropriability regime, firms differentiated themselves from potential free riders by offering complementary products or services that leverage their expertise as WR developers (e.g., Zott et al. 2011). In addition, the collaborative development of WR allowed companies to amortize the R\&D process across a large group of well-qualified partners (Chesbrough 2003), and it gave them a large user community from which they could significantly reduce the costs of product support and maintenance. However, such an approach also implied a wider field of competitors, which required alternative forms of business ingenuity. Given this context, we identified three main business models that emerged for WR over time as the technology became more mature (Bonvoisin et al. 2017; see Figure 3). 


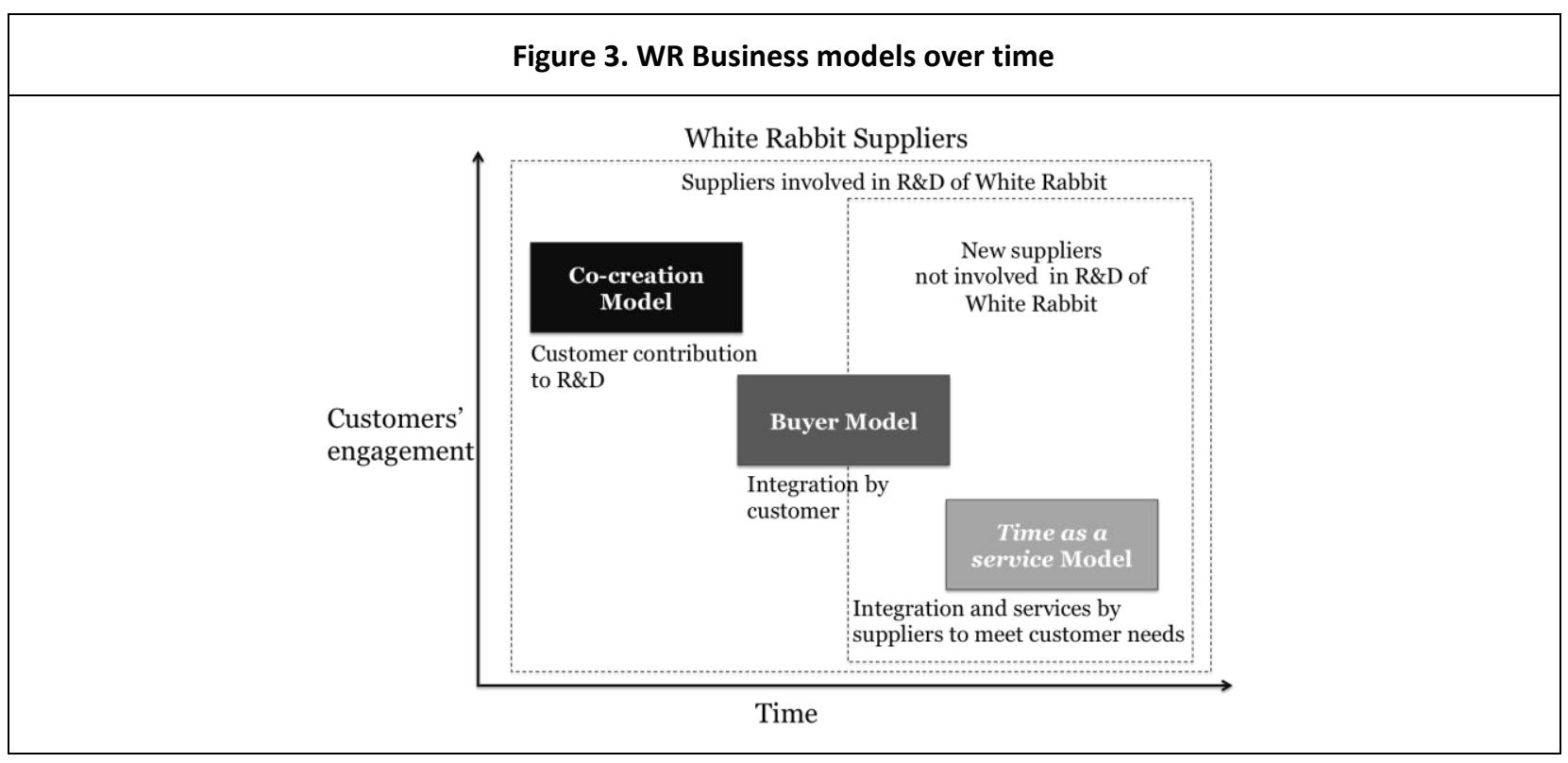

\section{Co-creation model}

Antecedents: The first business model that appears for WR is the co-creation model, where the customer participates in the R\&D process of WR. These are the scientific infrastructures that were part of the WR development process as well as the first purchasers of the hardware including CERN, GSI, and other scientific infrastructures. In keeping with what empirical studies describe for other OSS cases, those customers were more tolerant of usage difficulties and provided peer review of the technology to the community (Raasch et al. 2009). As CH1 explains," the testing was done by the final users of WR, who actually went on to buy the WR technology."

Processes: Under this model, the customer purchases WR hardware (product) and integrates the technology in their experimental setting. This was the prevailing business model applied for the first uptake of WR in the scientific industry. For instance: "We did feasibility studies and implemented WR for the European Space Agency to synchronize European Space Agency tracking stations" (CH1). 
This model reflects what research on collective models of innovation shows (e.g., Allen 1983; Hargrave and Van De Ven 2006; Murray and O’Mahony 2007). As early adopters of the technology, the engagement of these customers is high, providing peer-to-peer support through feedback (Lakhani and von Hippel 2004), bug reporting (Dahlander and Magnusson 2008) and design improvements. There is extensive evidence in the literature on the benefits that companies extract from contributions from community members to refine the technology (West and O’Mahony 2008). As RSE4 explains: "Customers founded bugs, they paid for the adaptations of designs, and you may find your competitors helping you."

Consequences: This first business model configuration had the effect of expanding the possibility of reusing the design in unexpected, experimental applications. "We are currently exploring potential applications of WR for quantum computing, but this is still in a scientific stage because as there is not a fully working quantum computing system operating yet" (CH1). Figure 4 highlights examples of the bugs and anomalies identified by early WR users in scientific infrastructures.

\begin{tabular}{|c|c|c|c|c|}
\hline \multicolumn{5}{|c|}{ Figure 4. Example of bugs reported by WR users (WR wiki) } \\
\hline Project & Date & Bug signaled by & Bug type & Bug description \\
\hline SPEC & & Early User & 3 & Mechanical problem SFP \\
\hline SPEC & & Producer & 1 & Design problem: supply voltage too low \\
\hline SPEC & 04-2015 & User & 2 & Too strong pull-down on reset line. Issue 1067 \\
\hline SVEC & 01-2014 & Producer & 1 & Documentation of VHDL code wrong \\
\hline FmcAdc100M14b4cha & 09-2013 & Producer & 1 & Production Test program, non-functional bug \\
\hline White Rabbit Switch & 2012 & Early User & 2,3 & Many different bugs \\
\hline White Rabbit Switch & 09-2013 & Early User & 2 & Setting of nsec part of TAl time \\
\hline White Rabbit Switch & 08-2013 & User & 2 & WR time from SPEC to NTP daemon. User wrote tool \\
\hline White Rabbit Switch & 08-2013 & User & 3 & Display of delay times failed for links over $100 \mathrm{~km}$ \\
\hline White Rabbit Switch & 09-2014 & Producer & 1 & Second producer improved quality of production documentation \\
\hline White Rabbit core & 09-2013 & User & 3 & Jumps in WR time when used over an out-of-spec length link \\
\hline White Rabbit core & $11-2013$ & User & 2 & $\begin{array}{l}\text { Jumps in WR time on } 1000 \mathrm{~km} \text { link. Bug in core. } \\
\text { Seen by user; another user corrected partially bug; } \\
\text { CERN made final corrections and simulations. }\end{array}$ \\
\hline White Rabbit NIC & 04-2015 & User & 2 & Error with high traffic load (Follow up message is not from current parent) \\
\hline
\end{tabular}




\section{Buyer model}

Antecedents: The second model appeared during the standardization process of WR technologies. As CH1 explains: "We never thought WR would have a potential market beyond scientific instrumentation. Our core business and customers were scientific infrastructures, and we were surprised to expand to other sectors and applications with WR. It was not until 2015 when WR evolved in the process of standardization, and there was proof of the possibilities that we realized the actual commercial potential of the technology." "Making WR open and disseminating what we produced together in the standardization process is helping us to attract clients" (CH2). As RSE4 further explains: "The standardization process provided opportunities for the small companies involved in WR development because they got advertising by the community."

Processes: Under this buyer model, customers come from diverse industry sectors, and they are not engaged in the R\&D process of WR, yet they purchase the product of one of the suppliers without any supplementary service (Pearce 2017). Within this business model, the customer completes the integration of WR in house. As Bij et al. $(2013$, p. 6) explained, to implement WR you also need firmware and driver software, as for the majority of users "the bare hardware is not usable. Even if a user can write this code, it is good to have working examples available. CERN did not provide user applications, but we see that companies selling the hardware start providing these in the form of starter kits."

Under this business model, as suppliers explain, "We compete on the quality of the final product because the diagrams of the components are the same" $(\mathrm{CH} 1)$. "Sharing the same recipe or specs for a product does not translate into the same quality product" $(\mathrm{CH} 2)$. Although the open source approach creates a more extensive market involving different suppliers, under this model the 
original developers stay ahead of less experienced followers. This is consistent with what happened with other open source cases (e.g., Arduino), where despite copycat versions of the technology made in China, sales from the founders continue to increase dramatically due to quality differences (Thompson 2008).

The customers under this model also include small and medium-size companies. As one supplier explained, these customers "rely on us, a little company, because today they can buy my WR product and equipment, and if they need an upgrade and my company disappears or goes bankrupt, they will have other options as they can rely on the community of WR firms to provide the product, even if I disappear" $(\mathrm{CH} 1)$. This was precisely what CERN was looking for: "some redundancy for their future provision of WR" (RSE1).

Consequences: Under this business model, firms are not able to make enough profit. "Here the margins are low because it is not like proprietary hardware where you have to cover the high R\&D invested by your company. Here the investment is distributed across companies, and then the price is low. So the differences here is that you apply a $50 \%$ overhead instead of $300 \%$, for instance" (CH2). "This model does not provide enough income, so we had to come up with another strategy to sell WR and exploit what we developed. Even if we sell hundreds of WR units, that is not enough to pay the 200 people in our company" (CH1).

\section{Time as a service model}

Antecedents: The third business model, and the last one to emerge, was the time-as-a-service model. This is the model that, at present, WR suppliers and new external suppliers that have not been engaged in WR development are currently exploring. "We think we are moving ahead of the market. We are exploring how to provide time and clock synchronization services to customers, which will be progressively needed in the coming few years" (CD1). This was the 
last business model to emerge; it first appeared when WR became progressively commercialized in diverse industries. "We are currently building our own solutions and services on top of WR" (CH1).

Processes: Under this model, the customer is approached by an intermediary organization (or WR supplier) that produces the product and provides diverse services, which include WR integration into the customer organization. It requires an understanding of a new industry and the specificities of customer needs. This model provides "a lot of custom and hybrid solutions that you cannot simply purchase through our website" (CD1). Here the margins are typically higher than in the other models and leverage a broader range of creative implementations of the technology in the diverse business settings. The supplier is not just a WR manufacturing firm but offers consulting, support and services, in line with what has been observed in other open source cases (Lerner and Tirole 2003), such as additional functionalities and software routines (remote monitoring, upgrades, time stamping, control applications, etc.). "Under this model each client is unique" (CD1). Suppliers sell unique expertise obtained through the design process of WR, where they gained not only substantial knowledge of the core WR technologies but also the ability to work with challenging clients such as CERN and other research infrastructures.

A further extension of this business model currently being explored is where the supplier loans the hardware free of charge; the customer pays for its usage and a set of additional services. "We don't know of anything that can guide us in this process of figuring out how to package WR. We are doing brainstorming a little blindly by listening to what customers need" (CD2). Another version of such a business model is when the WR customer itself provides WR services to its clients. In the example of financial services, customers are providing those services themselves; in the case of telecommunications, customers are providing the services in collaboration with WR supplier. As CA1 explains: "We are currently providing different WR services to our clients, 
which consists of High-Precision Timestamp File (what is my delta to faster competitors), and customers can now synchronize with our WR master and can now get UTC from our WR.” As CA1 further reveals: "We ask our customers for an average of 400 euros/month for those services." This business model is still incipient and is expected to grow: "We look forward to having more vendor support for WR in the future. This would enable full end-to-end WR time distribution" (CA1). As CA2 further explains: "We are confident enough to provide WR-based services to real, paying customers."

Consequences: Under the service model, due to the uniqueness of each client, and the vast diversity of sectors and business applications of the technology, suppliers are still struggling to "package" or standardize their services around WR: "We are struggling to find a common denominator for all our customers and generalize a WR service. I think the next few years will help us to overcome this challenge" (CD1). Under this business model, partnerships among firms emerge to provide innovative time services to end customers (e.g., "we are working with a telecommunications company, and we are jointly assessing the capability to use WR to provide time as a service to their end-customers at a country level” $\mathrm{CH} 1$ ).

\section{DISCUSSION}

WR, and by extension, complex OSH requiring industrial production (the second archetype defined in OSH), deviates from OSS on several dimensions, since hardware, as opposed to software, requires building a physical artifact. We discuss the implications of such differences for both the supply of the hardware (i.e., requisite mechanisms to apply the private-collective model to physical goods) and the implications for the commercialization of the hardware by the contributors to OSH (i.e., demand). An important caveat in the following discussion is the recognition that our case of WR represents a relatively extreme example of OSH, in that its 
complexity results in a long and expensive development cycle (8 years), combined with relatively higher costs of production (see Appendix). The research that does exist on OSH has tended to focus on lower-cost examples (Gibb 2014; Pearce 2012, 2014). As such, we can assume that the differences identified will be commensurate with product complexity and production costs.

\section{Deviations of OSH from OSS}

Both OSH and OSS can be generated by commercial or independent contributors, or a mixture of both (Bonvoisin et al. 2017). In this discussion we compare WR, and by extension complex OSH (second archetype), and thereby exclude DIY-hardware type OSH products developed by a community of individuals who are able to assemble the hardware at home with basic expertise and limited industrial support. Alternatively, we do find it meaningful to compare OSH with OSS driven by firms (Crowston et al. 2008; Henkel 2006; Lakhani and Wolf 2003).

First, it is important to highlight that the distinction between open source development of OSH and OSS does not fall into discrete categories as they might appear, as "hardware is becoming much more like software" (Thompson 2008). However, the in-depth examination through WR study suggests: 1) a number of qualitative differences (in substance), due to the different nature of the artifact developed and, in turn, the consequences for the development process; and 2) some quantitative differences between OSH and OSS that are a matter of degree pertaining to their prototyping and production.

The qualitative characteristics that distinguish complex OSH from OSS include:

1) Actors: OSH with product complexity requires firms that source components, manufacture and assemble the different parts and distribute them across the developer community to enable the design process, which includes improving the design, testing for quality, and 
fixing bugs. Thus, it requires manufacturing firms capable of building and distributing hardware across disperse community of developers. Typically, investments in OSS are made by users of that software (von Krogh and von Hippel 2006, p. 22). With complex hardware, you need both the users (the scientific infrastructures and future users) and the hardware manufacturers (suppliers) to collaborate during the development process. During the R\&D phase of WR, the scientific infrastructures purchased the prototypes of the industrial partners and collaborated to refine the technology. This is similar to other OSH (e.g., RepRap) reported in the literature: "If changes are made to the hardware, then everybody that's got hardware already built has to start again or modify it. There is some cost associated with this, which would not occur with software. They can just download it, and they got it" (Balka 2011 p. 75). Consequently, in OSH, there are no clear-cut distinctions between the phases of design, prototyping, and production. This implies additional expense as OSH requires a manufacturer constantly rebuilding within the design process, not merely when the design is finalized. Instead, different test versions are produced and released to the community at a cost for testing and improvement (Raasch et al. 2009). The Appendix 3 offers a table with all organizations and types that contributed to WR, according to the repository analysis, and the units of WR purchased by developers according to one of the WR manufacturers.

2) Costs: The marginal costs in software re-production approach zero, but in hardware the manufacturing costs of the physical artifact can be substantial. As mentioned above in pt. 1, physical prototyping is an integral part of the design process. In the case of WR, the unit costs of manufacturing WR switch is estimated by $\mathrm{CH} 1$ around 3,500 euros (see Appendix 3). As other OSH initiatives describe: "Software can be made with time, but hardware needs time and money" (“Open Source Hardware Bank - P2P Foundation” n.d.). Distribution costs are also incurred for delivering the products to the different WR users, and those costs vary 
according to geographic distances. Finally, OSH with significant marginal production costs is not a pure public good. Public goods are characterized by nonexcludability and nonrivalry. Physical products have some level of rivalry: if user $\mathrm{X}$ is using the hardware, user $\mathrm{Y}$ cannot use it.

3) Development process: The development of physical components requires that prototypes are distributed across users and manufacturers collaborating together in the hardware development. Building physical hardware entails revisions. In addition to the financial expense, this has implications for the development process, requiring firms capable of distributing low units of highly specific and highly changeable hardware to a geographically distributed community of organizations. Typically, early revisions identify problems to be fixed. When developers work to fix the code in OSS, the thing that "costs" is the time of the developer fixing the error. By contrast, OSH errors translate into broken or malfunctioning hardware. Although many of the tasks required for developing the hardware can be accomplished virtually, the design and production of the physical artifact requires physical spaces for the suppliers and face-to-face periodical exchanges within the community over time to align design and manufacturing activities.

Along with the qualitative differences between OSS and OSH, our results also shed light on some nuanced contrasts in terms of degree; that is. quantitative differences.

4) R\&D investment required: The costs incurred in both OSS and OSH are related to the loss of property rights, a loss that makes realizing an economic return on the private investments impossible. Initial R\&D investments for developing a first beta version in OSS can vary from low to high. OSH projects with high product complexity are initially significant compared to OSS. This requires effective incentives for developers to join the open development of the 
hardware, emphasizing stability of technology (standards) as well as profit-realization opportunities for participants.

5) Implementation: Diffusion and implementation costs in OSH are generally higher and increase commensurately with product complexity and specificity of the installation. The implementation costs for providing WR to different users is a result of the high specificity of scientific computing infrastructures, making technology implementation very context dependent (e.g., CERN's scientific network will be vastly different from LHAASO's). This effect might be exacerbated with WR adoption in other economic sectors such as financial markets or air traffic control.

\begin{tabular}{|c|c|c|}
\hline \multicolumn{3}{|c|}{ Table 4. Deviations of OSH from OSS } \\
\hline & OSS & OSH \\
\hline \multicolumn{3}{|c|}{ Qualitative differences } \\
\hline Actors & $\begin{array}{ll}- & \text { Developers- User firms } \\
\text { - } & \text { Developers- Independent } \\
\text { Individuals (paid or } \\
\text { volunteers) }\end{array}$ & $\begin{array}{l}\text { Developer and manufacturing } \\
\text { companies: } \\
\text { - Developers- User firms } \\
\text { - Developers- User } \\
\text { organizations } \\
\text { - Developers- Manufacturing } \\
\text { firms engaged in the design } \\
\text { and prototyping phase }\end{array}$ \\
\hline & Marginal costs $=0$ & $\begin{array}{c}\text { Marginal costs significantly higher } \\
\text { than } 0\end{array}$ \\
\hline Costs & No distribution costs & $\begin{array}{c}\text { Distribution costs in the } \\
\text { development and implementation } \\
\text { process context-dependent and } \\
\text { greater than } 0\end{array}$ \\
\hline Development process & Virtual work & $\begin{array}{c}\text { Virtual work combined with } \\
\text { physical spaces and face-to-face } \\
\text { meetings }\end{array}$ \\
\hline \multicolumn{3}{|c|}{ Quantitative differences } \\
\hline Initial R\&D investment & $\begin{array}{l}\text { Varies depending on product } \\
\text { complexity }\end{array}$ & $\begin{array}{l}\text { Varies depending on product } \\
\text { complexity }\end{array}$ \\
\hline Implementation & $\begin{array}{c}\text { Diffusion and implementation } \\
\text { costs lower }\end{array}$ & $\begin{array}{c}\text { Diffusion and implementation } \\
\text { costs higher and highly context- } \\
\text { dependent }\end{array}$ \\
\hline
\end{tabular}




\section{Implications of the Deviations for OSH Supply}

Scholars have pointed out that the challenges of transporting the open source model of information goods to tangible objects are due to the dissimilarity of the objects and their characteristics (Balka 2011). WR is a complex OSH with high initial R\&D costs distributed across firms (see Appendix 1). A combination of mechanisms was required to convince qualified contributors of the long-term viability and potential financial returns. Simply publishing development goals and expecting contributions for intrinsic rewards would in all probability not have been a successful approach. Similarly, the high development costs require a sufficient number of qualified contributors to amortize the development costs broadly. The combination of these two factors requires active recruitment by a legitimate sponsor who can mitigate perceived risks. As RSE4 explains: “OSH is new and not always understood. You need to explain to companies the opportunities and risks. Companies think they compete with assembly companies. We ask only engineering companies that can also give support (guarantee, repair, improve). It needs time from us and guts from companies."

These deviations of OSH from OSS (Table 4) lead us to revisit the assumptions of the privatecollective model (von Hippel and von Krogh 2003) as follows:

The private-collective model appears if:

i. Innovation diffusion benefits are higher than innovation loss of profit as a result of free revealing, and

ii. Process benefits obtained by contributors are higher than free-riders' benefits.

As argued, the WR case represents a unique example of OSH given the product's complexity and requirement for industrial production, and thus initial R\&D investment by all organizations. We can, therefore, append the following qualifiers: 
a) Greater R\&D investment of the OSH increases the loss of profit for the supplier and is therefore negatively related to free revealing.

b) In our case, we argued that R\&D investment and product complexity are positively related.

As such, we formulate the following propositions that describe the underlying conditions for a private-collective model to appear in OSH development, and how these vary under conditions of increasing R\&D investment and product complexity.

- P1 For OSH with higher R\&D investment and product complexity, greater financial subsidies are required to encourage free revealing by contributors (M1 Sponsorship).

- P2 For OSH with higher R\&D investment and product complexity, explicit tolerance of open and proprietary technologies is required to encourage free revealing by contributors (M2 open and closed IP).

- P3 For OSH with higher R\&D investment and product complexity, more contributions from sophisticated users or sponsors are required to encourage free revealing by contributors (M3 grandfathering, engagement \& collaborative development).

- P4 For OSH with higher R\&D investment and product complexity, more institutional legitimacy and reputation of users is required to encourage free revealing by contributors (M4 branding and reputation).

- P5 For OSH with higher R\&D investment and product complexity, more technological stability is required to encourage free revealing by contributors (M5 standards).

As stated, participation in the development of OSH confers process benefits of increased knowledge and expertise. Accordingly, we formulate the following propositions that influence the ability of contributors to realize returns that are greater than those of free riders: 
- P6 For contributors to OSH with higher R\&D investment and product complexity, knowledge derived through the development process enables greater differentiation from competitors.

- P7 For contributors to OSH with higher R\&D investment and product complexity, reputation derived through the development process enables greater differentiation from competitors.

In the private-collective model, the impact on social welfare was the "best of both worlds: public goods are produced at private expense. Innovators relinquish control of knowledge produced, but at the same time gain private profits so public subsidy is not required" (von Hippel and von Krogh 2003, p. 304). In the case of WR, the characteristics of this open scientific hardware implied that such result was possible ("the best of both worlds") with some "concessions" to the private-collective model. These modifications are illustrated in Figure 5.

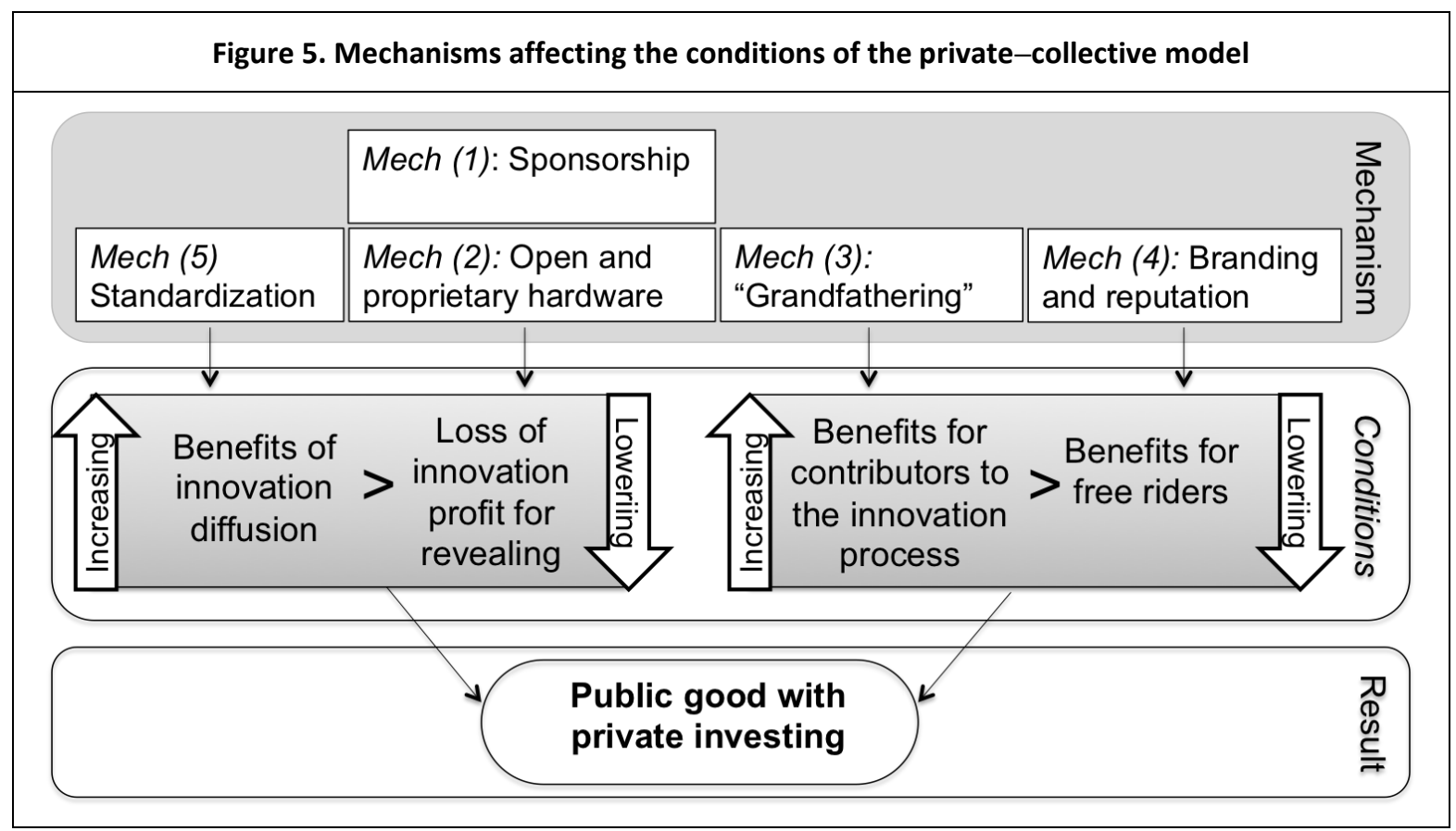




\section{Implications of the Deviations for OSH Demand}

The extension of the private-collective model to OSH also has implications for the open source business model literature, shedding light on emerging open business strategies of innovation for digital designs and tangible products. Research on open source has been mostly focused on the characteristics of the development process of OSS projects (i.e., on the supply side), but far less has been investigated in the consequences of the OSS for for-profit companies when commercializing OSS (Ågerfalk et al. 2015).

OSH presents idiosyncrasies in how firms can amortize their R\&D investment in developing a complex technology and disclosing the design in the open domain. As the evolution of the business models in WR shows, being a contributor to a public good increases a firm's possibility of benefiting from a widespread adoption of the innovation (Allen 1983), especially in the early stages of the technology market adoption. As a result, such firms can gain a competitive advantage over other firms that have not contributed to the technology, especially when there is an open standard into which companies can incorporate other technologies and solutions and gain additional advantages (e.g., Economides and Katsamakas 2006).

From the WR case, an interesting hypothesis can be made: The development and adoption of OSH will always follow a similar, commercial evolution. It is logical that the organizations that seek to develop the technologies will be its first users. They have a specific problem to be addressed and have taken the initiative to develop the solution. In the second phase of adoption, we find other scientific research institutions with similar time-synchronization challenges or first early adopters in other industries, yet with sufficient engineering expertise to acquire and implement the technologies as described in the buyer model. Finally, in the service model, we 
see more heterogeneous organizations whose operational focus is far from the scientific research community, and may, therefore, have insufficient expertise to implement the technology in a traditional purchase transaction. Instead, they require the expertise of the WR community to customize and operate the technology in a different market context. Future research can examine this evolution as the population of OSH projects grows.

\section{CONCLUSION}

Big-science research infrastructures develop some of the most sophisticated technologies in existence. Mechanisms that can facilitate the transfer and commercialization of these technologies have vast potential to contribute to economic and social welfare. WR is a very successful example of this. WR, being OSH, differs from traditional OSS due to its tangible nature and its product complexity, attributes that affect its initial R\&D investment, costs, actors that contribute, characteristics of the development process and implementation. Under normal conditions, suppliers of WR technologies would not reveal innovations. However, through CERN's interventions WR was able to stimulate revelation and investment by suppliers. The case provides us with a unique opportunity to revisit the private-collective model and revise its conditions relevant to OSH. In conditions of high product complexity of physical products and greater R\&D investment, specific mechanisms can be designed and implemented to facilitate the emergence of the private-collective model by decreasing costs and increasing benefits. We additionally identified a pattern in the evolution of diverse business model configurations that might be replicated in other OSH examples. 


\section{REFERENCES}

Ackerman, J. R. 2008. “Toward Open Source Hardware," University of Dayton Law Review (34), pp. 183-222.

Ågerfalk, P. J., and Fitzgerald, B. 2008. "Outsourcing to an Unknown Workforce: Exploring Opensurcing as a Global Sourcing Strategy," MIS Quarterly (32:2), pp. 385-409. (https://doi.org/10.2307/25148845).

Ågerfalk, P. J., Fitzgerald, B., and Stol, K.-J. 2015. Software Sourcing in the Age of Open, SpringerBriefs in Computer Science, Cham: Springer International Publishing. (https://doi.org/10.1007/978-3-319-17266-8).

Allen, R. C. 1983. "Collective Invention," Journal of Economic Behavior \& Organization (4:1), pp. 1-24. (https://doi.org/10.1016/0167-2681(83)90023-9).

Amit, R., and Zott, C. 2001. "Value Creation in E-Business," Strategic Management Journal (22:6-7), pp. 493-520. (https://doi.org/10.1002/smj.187).

Autio, E. 2014. Innovation from Big Science: Enhancing Big Science Impact Agenda, Department of Business, Innovation \& Skills. Imperial College Business School, p. 76.

Autio, E., Bianchi-Streit, M., and Hameri, A.-P. 2003. Technology Transfer and Technological Learning through CERN's Procurement Activity, CERN Yellow Reports: Monographs, Geneva: CERN.

Baden, T., Chagas, A. M., Gage, G., Marzullo, T., Prieto-Godino, L. L., and Euler, T. 2015. "Open Labware: 3-D Printing Your Own Lab Equipment," PLOS Biology (13:3), p. e1002086. (https://doi.org/10.1371/journal.pbio.1002086).

Baldwin, C. Y., and Clark, K. B. 2006. "The Architecture of Participation: Does Code Architecture Mitigate Free Riding in the Open Source Development Model?," Management Science (52:7), pp. 1116-1127. (https://doi.org/10.1287/mnsc.1060.0546).

Balka, K. 2011. Open Source Product Development: The Meaning and Relevance of Openness, Springer Science \& Business Media.

Balka, K., Raasch, C., and Herstatt, C. 2009. "Open Source Enters the World of Atoms: A Statistical Analysis of Open Design," First Monday (14:11). (https://doi.org/10.5210/fm.v14i11.2670).

Balka, K., Raasch, C., and Herstatt, C. 2010. "How Open Is Open Source? - Software and Beyond: HOW OPEN IS OPEN SOURCE?," Creativity and Innovation Management (19:3), pp. 248-256. (https://doi.org/10.1111/j.1467-8691.2010.00569.x).

Benkler, Y. 2006. The Wealth of Networks: How Social Production Transforms Markets and Freedom Contract: Freedom in the Commons, New Haven, UNITED STATES: Yale University Press. (http://ebookcentral.proquest.com/lib/georgetown/detail.action?docID=3419996).

Bij, E. van der, Arruat, M., Cattin, M., Daniluk, G., Cobas, J. D. G., Gousiou, E., Lewis, J., Lipinski, M. M., Serrano, J., Stana, T., Voumard, N., and Wlostowski, T. 2013. "How to Create Successful Open Hardware Projects - About White Rabbits and Open Fields," Journal of Instrumentation (8:12), pp. C12021-C12021. (https://doi.org/10.1088/1748- 
0221/8/12/C12021).

Bonaccorsi, A., and Rossi, C. 2003. "Why Open Source Software Can Succeed," Research Policy (32:7), Open Source Software Development, pp. 1243-1258. (https://doi.org/10.1016/S0048-7333(03)00051-9).

Bonvoisin, J., Mies, R., Boujut, J.-F., and Stark, R. 2017. "What Is the 'Source' of Open Source Hardware?," Journal of Open Hardware (1:1), p. 5. (https://doi.org/10.5334/joh.7).

Boudreau, K. J., and Lakhani, K. R. 2015. “'Open’ Disclosure of Innovations, Incentives and Follow-on Reuse: Theory on Processes of Cumulative Innovation and a Field Experiment in Computational Biology," Research Policy (44:1), pp. 4-19. (https://doi.org/10.1016/j.respol.2014.08.001).

Boujut, J.-F. 2015. “Open Design Platforms for Open Source Product Development: Current State and Requirements," in Proceedings of the 20th International Conference on Engineering Design (ICED 15), Milan, Italy, pp. 11-22.

Brynjolfsson, E. 2014. The Second Machine Age: Work, Progress, and Prosperity in a Time of Brilliant Technologies, (First Edition.), New York: WWNorton \& Company.

Buechley, L., and Hill, B. M. 2010. "LilyPad in the Wild: How Hardware's Long Tail Is Supporting New Engineering and Design Communities," in Proceedings of the 8th ACM Conference on Designing Interactive Systems, DIS '10, New York, NY, USA: ACM, pp. 199-207. (https://doi.org/10.1145/1858171.1858206).

Chesbrough, H. 2003. Open Innovation: The New Imperative for Creating and Profiting from Technology, Harvard Business Press.

Chesbrough, H. 2007. "Business Model Innovation: It's Not Just about Technology Anymore," Strategy \& Leadership (35:6), pp. 12-17. (https://doi.org/10.1108/10878570710833714).

Chesbrough, H. 2010. "Business Model Innovation: Opportunities and Barriers," Long Range Planning (43:2), Business Models, pp. 354-363. (https://doi.org/10.1016/j.lrp.2009.07.010).

Chesbrough, H. W. 2006. Open Innovation: The New Imperative for Creating And Profiting from Technology, (Edición: First Trade Paper.), Boston, Mass: Harvard Business School Press.

Corbin, J. M., and Strauss, A. 1990. "Grounded Theory Research: Procedures, Canons, and Evaluative Criteria," Qualitative Sociology (13:1), pp. 3-21. (https://doi.org/10.1007/BF00988593).

Crowston, K., Wei, K., Howison, J., and Wiggins, A. 2008. "Free/Libre Open-Source Software Development: What We Know and What We Do Not Know," ACM Comput. Surv. (44:2), 7:1-7:35. (https://doi.org/10.1145/2089125.2089127).

Dahlander, L., and Magnusson, M. 2008. "How Do Firms Make Use of Open Source Communities?," Long Range Planning (41:6), pp. 629-649. (https://doi.org/10.1016/j.lrp.2008.09.003).

Dahlander, L., and Wallin, M. W. 2006. "A Man on the inside: Unlocking Communities as Complementary Assets," Research Policy (35:8), Special Issue Commemorating the 20th Anniversary of David Teece's Article, "Profiting from Innovation", in Research Policy, 
pp. 1243-1259. (https://doi.org/10.1016/j.respol.2006.09.011).

Dedrick, J., and West, J. 2003. "Why Firms Adopt Open Source Platforms: A Grounded Theory of Innovation and Standards Adoption," Proceedings of the Workshop on Standard Making: A Critical Research Frontier for Information Systems, pp. 236-257.

Economides, N. 1996. “The Economics of Networks,” Int. J. Ind. Organ., p. 27.

Economides, N., and Katsamakas, E. 2006. "Two-Sided Competition of Proprietary vs. Open Source Technology Platforms and the Implications for the Software Industry," Management Science (52:7), pp. 1057-1071.

Edwards. 2014. "National Instruments Sets out Plans for Real-Time Distributed Cyber-Physical Systems," Tech Design Forum, , August 9. (http://www.techdesignforums.com/blog/2014/08/09/labview-white-rabbit-distributedreal-time/, accessed November 9, 2018).

Eisenhardt, K. M. 1989. "Building Theories from Case Study Research,” Academy of Management Review (14:4), pp. 532-550. (https://doi.org/10.5465/amr.1989.4308385).

Eisenhardt, K. M., and Graebner, M. E. 2007. "Theory Building From Cases: Opportunities And Challenges," Academy of Management Journal (50:1), pp. 25-32. (https://doi.org/10.5465/amj.2007.24160888).

Fauchart, E., and von Hippel, E. 2008. "Norms-Based Intellectual Property Systems: The Case of French Chefs,” Organization Science (19:2), pp. 187-201.

Feller, J., and Fitzgerald, B. 2001. Understanding Open Source Software Development, (1 edition.), London; Boston: Addison-Wesley Professional.

Fink, M. 2003. Business and Economics of Linux and Open Source. (https://dl.acm.org/citation.cfm?id=572540).

Fitzgerald. 2006. “The Transformation of Open Source Software,” MIS Quarterly (30:3), p. 587. (https://doi.org/10.2307/25148740).

Gibb, A. 2014. Building Open Source Hardware: DIY Manufacturing for Hackers and Makers, (1 edition.), Upper Saddle River, NJ: Addison-Wesley Professional.

Hann, I.-H., Roberts, J., and Slaughter, S. 2004. "Why Developers Participate in Open Source Software Projects: An Empirical Investigation," ICIS 2004 Proceedings, p. 11.

Hansen, A., and Howard, T. J. 2013. "The Current State of Open Source Hardware: The Need for an Open Source Development Platform," in ICoRD'13, Lecture Notes in Mechanical Engineering, A. Chakrabarti and R. V. Prakash (eds.), Springer India, pp. 977-988.

Hargrave, T. J., and Van De Ven, A. H. 2006. "A Collective Action Model of Institutional Innovation," Academy of Management Review (31:4), pp. 864-888. (https://doi.org/10.5465/amr.2006.22527458).

Harhoff, D., Scherer, F. M., and Vopel, K. 2003. "Citations, Family Size, Opposition and the Value of Patent Rights," Research Policy (32:8), pp. 1343-1363. (https://doi.org/10.1016/S0048-7333(02)00124-5).

Hars, A., and Ou, Shaosong. 2002. "Working for Free? Motivations for Participating in OpenSource Projects," International Journal of Electronic Commerce (6:3), pp. 25-39. (https://doi.org/10.1080/10864415.2002.11044241). 
Henkel, J. 2006. "Selective Revealing in Open Innovation Processes: The Case of Embedded Linux," Research Policy (35:7), pp. 953-969.

(https://doi.org/10.1016/j.respol.2006.04.010).

Hertel, G., Niedner, S., and Herrmann, S. 2003. "Motivation of Software Developers in Open Source Projects: An Internet-Based Survey of Contributors to the Linux Kernel," Research Policy (32:7), Open Source Software Development, pp. 1159-1177. (https://doi.org/10.1016/S0048-7333(03)00047-7).

von Hippel, E. 2005. "Democratizing Innovation: The Evolving Phenomenon of User Innovation," Journal Für Betriebswirtschaft (55:1), pp. 63-78. (https://doi.org/10.1007/s11301-004-0002-8).

von Hippel, E., and Katz, R. 2002. "Shifting Innovation to Users via Toolkits," Management Science (48:7), pp. 821-833. (https://doi.org/10.1287/mnsc.48.7.821.2817).

von Hippel, E., and von Krogh, G. 2003. 'Open Source Software and the 'Private-Collective' Innovation Model: Issues for Organization Science,” Organization Science (14:2), pp. 209-223.

Howard, T. J., Achiche, S., Özkil, A., and McAloone, T. C. 2012. “Open Design and Crowdsourcing: Maturity, Methodology and Business Models," DS 70: Proceedings of Design 2012, the 12th International Design Conference, Dubrovnik, Croatia.

Hurwicz, L. 1973. "The Design of Mechanisms for Resource Allocation," The American Economic Review (63:2), pp. 1-30.

Jacobs, M. 2007. "Product Complexity: A Definition and Impacts on Operations," Decision Line (38:5). (https://ecommons.udayton.edu/mis_fac_pub/94).

Jeppesen, L. B., and Frederiksen, L. 2006. "Why Do Users Contribute to Firm-Hosted User Communities? The Case of Computer-Controlled Music Instruments," Organization Science (17:1), pp. 45-63. (https://doi.org/10.1287/orsc.1050.0156).

Kogut, B., and Metiu, A. 2001. “Open- Source Software Development and Distributed Innovation," Oxford Review of Economic Policy (17:2), pp. 248-264. (https://doi.org/10.1093/oxrep/17.2.248).

Krogh, G. von, and Hippel, E. von. 2006. "The Promise of Research on Open Source Software," Management Science (52:7,), pp. 975-983.

Lakhani, K. R., and von Hippel, E. 2004. 'How Open Source Software Works: 'Free' User-toUser Assistance," in Produktentwicklung Mit Virtuellen Communities: Kundenwünsche Erfahren Und Innovationen Realisieren, C. Herstatt and J. G. Sander (eds.), Wiesbaden: Gabler Verlag, pp. 303-339. (https://doi.org/10.1007/978-3-322-84540-5_13).

Lakhani, K. R., and Wolf, R. G. 2003. "Why Hackers Do What They Do: Understanding Motivation and Effort in Free/Open Source Software Projects," SSRN Scholarly Paper No. ID 443040, SSRN Scholarly Paper, Rochester, NY: Social Science Research Network, September 1. (https://papers.ssrn.com/abstract=443040).

Lerner, J., and Tirole, J. 2003. "Some Simple Economics of Open Source," The Journal of Industrial Economics (50:2), pp. 197-234. (https://doi.org/10.1111/1467-6451.00174).

Lipiński, M., Włostowski, T., Serrano, J., and Alvarez, P. 2011. "White Rabbit: A PTP 
Application for Robust Sub-Nanosecond Synchronization," in Control and Communication 2011 IEEE International Symposium on Precision Clock Synchronization for Measurement, , September, pp. 25-30. (https://doi.org/10.1109/ISPCS.2011.6070148).

Mahadevan, B. 2000. "Business Models for Internet-Based E-Commerce: An Anatomy," California Management Review (42:4), pp. 55-69. (https://doi.org/10.2307/41166053).

Markoff, J. 2018. "Time Split to the Nanosecond Is Precisely What Wall Street Wants," The New York Times. (https://www.nytimes.com/2018/06/29/technology/computer-networksspeed-nasdaq.html).

Maxwell, J. A. 2013. Qualitative Research Design: An Interactive Approach, (3rd ed.), Applied Social Research Methods ; 41, Thousand Oaks, Calif: SAGE Publications.

Moreira, P., Serrano, J., Wlostowski, T., Loschmidt, P., and Gaderer, G. 2009. "White Rabbit: Sub-Nanosecond Timing Distribution over Ethernet," in In Proc. of the International IEEE Symposium on PrecisionClock Synchronization for Measurement, Control and Communication, ISPCS, pp. 58-62.

Murray, F., and O'Mahony, S. 2007. "Exploring the Foundations of Cumulative Innovation: Implications for Organization Science," Organization Science (18:6), pp. 1006-1021.

Nuvolari, A. 2004. "Collective Invention during the British Industrial Revolution: The Case of the Cornish Pumping Engine," Cambridge Journal of Economics (28:3), pp. 347-363. (https://doi.org/10.1093/cje/28.3.347).

Oberloier, S., and Pearce, J. 2017. "General Design Procedure for Free and Open-Source Hardware for Scientific Equipment,” Designs (2:1), p. 2. (https://doi.org/10.3390/designs2010002).

Open Source Hardware Association (https://www.oshwa.org/definition/)

Open Source Hardware Bank - P2P Foundation. (https://wiki.p2pfoundation.net/Open_Source_Hardware_Bank, accessed February 10, 2019).

Ostrom, E. 1990. Governing the Commons: The Evolution of Institutions for Collective Action, Cambridge University Press.

Pearce, J. M. 2012. "Building Research Equipment with Free, Open-Source Hardware," Science (337:6100), pp. 1303-1304. (https://doi.org/10.1126/science.1228183).

Pearce, J. M. 2014. "Laboratory Equipment: Cut Costs with Open-Source Hardware," Nature, , January 29. (https://doi.org/10.1038/505618d).

Pearce, J. M. 2017. "Emerging Business Models for Open Source Hardware," Journal of Open Hardware (1:1). (https://doi.org/10.5334/joh.4).

Raasch, C., and Herstatt, C. 2011. "How Companies Capture Value from Open Design," International Journal of Information and Decision Sciences (3:1), pp. 39-53. (https://doi.org/10.1504/IJIDS.2011.03884).

Raasch, C., Herstatt, C., and Balka, K. 2009. "On the Open Design of Tangible Goods," $R \& D$ Management (39:4), pp. 382-393. (https://doi.org/10.1111/j.1467-9310.2009.00567.x).

Rifkin, J. 2014. The Zero Marginal Cost Society: The Internet of Things, the Collaborative 
Commons, and the Eclipse of Capitalism, (First edition.), New York: Palgrave Macmillan.

Rodriguez-Toro, C. A., Jared, G., and Swift, K. 2004. "Product- Development Complexity Metrics: A Framework for Proactive - DFA Implementation," DS 32: Proceedings of DESIGN 2004, the 8th International Design Conference, Dubrovnik, Croatia..

Rogers, E. M. 1995. "Diffusion of Innovations: Modifications of a Model for Telecommunications," in Die Diffusion von Innovationen in Der Telekommunikation, Schriftenreihe Des Wissenschaftlichen Instituts Für Kommunikationsdienste, M.-W. Stoetzer and A. Mahler (eds.), Berlin, Heidelberg: Springer Berlin Heidelberg, pp. 25-38. (https://doi.org/10.1007/978-3-642-79868-9_2).

Rosenkopf, L., Metiu, A., and George, V. P. 2001. "From the Bottom Up? Technical Committee Activity and Alliance Formation," Administrative Science Quarterly (46:4), p. 748. (https://doi.org/10.2307/3094830).

Schweisfurth, T., Raasch, C., and Herstatt, C. 2011. "Free Revealing in Open Innovation: A Comparison of Different Models and Their Benefits for Companies," International Journal of Product Development (13:2), p. 95. (https://doi.org/10.1504/IJPD.2011.038867).

Shah, S. K. 2006. "Motivation, Governance, and the Viability of Hybrid Forms in Open Source Software Development," Management Science (52:7), pp. 1000-1014. (https://doi.org/10.1287/mnsc.1060.0553).

Siggelkow, N. 2007. "Persuasion With Case Studies," Academy of Management Journal (50:1), pp. 20-24. (https://doi.org/10.5465/amj.2007.24160882).

Stuermer, M., Spaeth, S., and von Krogh, G. 2009. "Extending Private-Collective Innovation: A Case Study," R\&D Management (39:2), pp. 170-191. (https://doi.org/10.1111/j.14679310.2009.00548.x).

Teece, D. J. 1986. "Profiting from Technological Innovation: Implications for Integration, Collaboration, Licensing and Public Policy," Research Policy (15:6), pp. 285-305. (https://doi.org/10.1016/0048-7333(86)90027-2).

Thompson, C. 2008. Build It. Share It. Profit. Can Open Source Hardware Work?, p. 9.

Torvalds, L., and Diamond, D. 2002. Just for Fun: The Story of an Accidental Revolutionary, New York [etc.: HarperBusiness.

Van Der Bij, E. 2018. “Open Hardware Repository | Wiki | Newsletter 2018 09,”, September 5. (https://www.ohwr.org/projects/white-rabbit/wiki/newsletter-2018-09\#LHAASO-Chinacurrently-40-nodes-and-4-switches-used-operationally-6734-nodes-and-564-switches-tobe-used-in-the-final-installation, accessed November 9, 2018).

Weinberg, A. M. 1967. "Reflections on Big Science," Eweb:1470. (http://dx.doi.org/10.1119/1.1974420).

West, J. 2003. "How Open Is Open Enough?," Research Policy (32:7), pp. 1259-1285. (https://doi.org/10.1016/S0048-7333(03)00052-0).

West, J., and Gallagher, S. 2006. "Challenges of Open Innovation: The Paradox of Firm Investment in Open-Source Software," $R$ and D Management (36:3), pp. 319-331. 
(https://doi.org/10.1111/j.1467-9310.2006.00436.x).

West, J., and Kuk, G. 2014. "Proprietary Benefits from Open Communities: How MakerBot Leveraged Thingiverse in 3D Printing," D Printing, p. 27.

West, J., and O'mahony, S. 2008. "The Role of Participation Architecture in Growing Sponsored Open Source Communities," Industry and Innovation (15:2), pp. 145-168. (https://doi.org/10.1080/13662710801970142).

Widomski, T., Borgulski, K., and Użycki, P. 2018. Faults of Synchronization Based on GNSS Receivers and Ethernet NTP/PTP Network, p. 13.

World Intellectual Property Organization. 2010. “Managing IP at CERN," WIPO Magazine (6/2010). (https://www.wipo.int/wipo_magazine/en/2010/06/article_0003.html).

Yin, R. K. 2003. Case Study Research: Design and Methods, SAGE.

Zhihao, Z. 2017. "Array Could Help Solve Cosmic Puzzle----The Large High Altitude Air Shower Observatory,", June 12. (http://english.ihep.cas.cn/lhaaso/doc/2512.html, accessed November 9, 2018).

Zott, C., Amit, R., and Massa, L. 2011. "The Business Model: Recent Developments and Future Research,” Journal of Management (37:4), pp. 1019-1042. (https://doi.org/10.1177/0149206311406265). 


\section{APPENDIX}

Appendix 1. Constructs definition

\begin{tabular}{|c|c|}
\hline \multicolumn{2}{|r|}{ Table 5. Constructs definition } \\
\hline Construct & Definition \\
\hline Big Science & Big science refers to large-scale and capital-intensive research facilities (Weinberg 1967) \\
\hline Business Model & $\begin{array}{l}\text { Business models are described as "a mechanism that connects a firm's (innovative) technology to customer } \\
\text { needs, and/or to other firm resources (e.g., technologies)" (Zott et al. 2011 p.21) }\end{array}$ \\
\hline DIY & $\begin{array}{l}\text { DIY is the abbreviation for "do-it-yourself," and in the framework of hardware, it refers to gadgets for hobbyists } \\
\text { or designs shared by individuals that can be easily built and assembled by each developer, usually with the } \\
\text { support of 3-D printing machines (Hansen and Howard 2013). }\end{array}$ \\
\hline Free Revealing & $\begin{array}{l}\text { When the provision of access to proprietary information "is based neither on market transactions nor on } \\
\text { employment or cooperation contracts and is typically not restricted to a pre-specified audience" (Schweisfurth } \\
\text { et al. } 2011 \text { p.98) }\end{array}$ \\
\hline Free Rider & $\begin{array}{l}\text { "Free rider" refers to the phenomenon whereby "someone profits from open source without reciprocating" } \\
\text { (Ågerfalk and Fitzgerald } 2008 \text { p.388). The free-rider phenomenon contravenes the values of reciprocity and } \\
\text { fulfillment of mutual expectations in the open source model (von Hippel and von Krogh 2003). }\end{array}$ \\
\hline $\begin{array}{l}\text { Intrinsic and Extrinsic } \\
\text { Motivation }\end{array}$ & $\begin{array}{l}\text { Motivation is considered extrinsic if needs are satisfied indirectly, primarily through monetary compensation } \\
\text { (Osterloh and Frey, 1998). On the other hand, motivation is considered intrinsic "when an activity is } \\
\text { undertaken for one's immediate need satisfaction" (Bonaccorsi and Rosi, 2006, p.41). In particular intrinsic } \\
\text { motivations can draw from the pleasure of performing an activity (Kuster et al., 2002). }\end{array}$ \\
\hline Mechanism & $\begin{array}{l}\text { Mechanism refers to the compatibility of incentives towards desired objectives where participants act } \\
\text { rationally (Hurwicz 1973) }\end{array}$ \\
\hline $\begin{array}{l}\text { Open Source Software } \\
\text { (OSS) }\end{array}$ & $\begin{array}{l}\text { Open source software (OSS) is defined as software released under the terms of a license that allows the } \\
\text { licensee to use, modify and redistribute, either gratis or for a fee (Ågerfalk, Fitzgerald and Stol, 2015) } \\
\text { OSS can be characterized as a privately-produced public good (O'Mahony 2003) } \\
\text { The difference between free software and OSS, according to the leader of the free software movement, } \\
\text { Richard Stallman, is that "Open source is a development methodology; free software is a social movement" }\end{array}$ \\
\hline
\end{tabular}




\begin{tabular}{|c|c|}
\hline & $\begin{array}{l}\text { (Stallman, } 2016 \text { p.1). The focus of the present paper is on research about the development processes, which } \\
\text { are acknowledged by participants to be fundamentally similar hence we will use the term OSS (Free Software } \\
\text { Foundation, 2019) (Crowston et al., 2008) }\end{array}$ \\
\hline $\begin{array}{l}\text { Open Source Hardware } \\
\text { (OSH) }\end{array}$ & $\begin{array}{l}\text { OSH is a term for hardware or tangible artifacts - machines, devices, or other physical things_-whose design } \\
\text { is made publicly available in a way that anyone can study, modify, distribute, make and sell the design or } \\
\text { hardware based on that design (OSH Association) }\end{array}$ \\
\hline $\begin{array}{l}\text { Open Source Model of } \\
\text { Innovation }\end{array}$ & $\begin{array}{l}\text { Open Source refers to the situation when an actor provides "access [to proprietary information] to all } \\
\text { interested agents without the imposition of any direct payment" (Harhoff et al. 2003), p. 1754). }\end{array}$ \\
\hline $\begin{array}{l}\text { Private Collective Model of } \\
\text { Innovation }\end{array}$ & $\begin{array}{l}\text { The open source model has been described as a private-collective model of innovation (von Hippel and von } \\
\text { Krogh 2003). The private-collective model occurs when public goods are produced through private } \\
\text { contributions without any direct commercial compensation. }\end{array}$ \\
\hline Product Complexity & $\begin{array}{l}\text { Product complexity is defined as "a design state resulting from the multiplicity of, and relatedness among, } \\
\text { product architectural elements" (Jacobs } 2007 \mathrm{p} \text {. } 7 \text { ). This characteristic affects the process of development of } \\
\text { a given hardware product because it determines whether production can take place in either DIY or an } \\
\text { industrial production setting. Product complexity also relates to design effort in terms of resources consumed } \\
\text { and process duration (Rodriguez-Toro et al. 2004). }\end{array}$ \\
\hline Public Good & $\begin{array}{l}\text { Public good is characterized by nonexcludability and nonrivalry (Harhoff et al. 2003; von Hippel and von } \\
\text { Krogh 2003; von Krogh and von Hippel 2006; Lakhani and von Hippel 2004; Lerner and Tirole 2003) }\end{array}$ \\
\hline Vendor Lock-In & $\begin{array}{l}\text { Vendor lock-in refers to a situation where a customer is dependent on a vendor for products and services and } \\
\text { in the case the customer wants to change to a new vendor there are significant switching costs. }\end{array}$ \\
\hline WR Suppliers & Individuals or companies that sell WR products or services based on WR technology to someone else. \\
\hline WR Users & ies that buy WR technology or WR services to another individual or organization. \\
\hline
\end{tabular}




\section{Appendix 2. WR within OSH landscape}

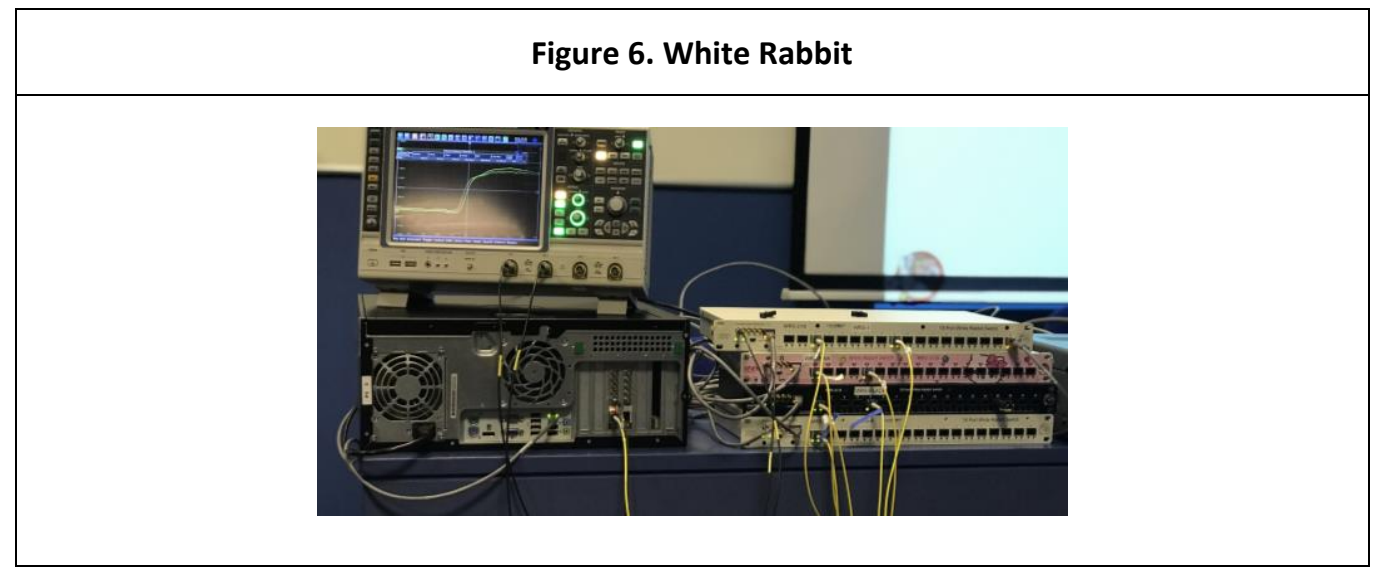

The present study refers to the second archetype of OSH, which includes forms of complex electronic hardware (but also mechanical, construction, medical, optical, agricultural or textile hardware) which require external manufacturers and reach quality standards of conventional industrial product development (see Section 2, Theoretical background). We refer to hardware that requires companies with expertise in manufacturing hardware to provide and distribute across the developer community the physical artifacts during the development process.

Within this category there is a wide range of examples that span from Lilypad to Oscar project. Lilypad was an academic project at MIT that developed a flexible electronic chipboard, adapted from Arduino, that was sought to be used in electronic textiles and became commercially available through SparkFun manufacturer; it generated significant markets supported and scaled up by online communities (Buechley and Hill 2010). MIT institutional networks were the primary means used to distribute the designs, and since then multiple chipset versions have been developed, including a wireless radio connection now integrated into the LilyPad kit and commercially available worldwide (Buechley and Hill 2010). A second example could be OScar project, which consists in a complete car openly designed by a community of developers and suppliers that is open for production; it was initiated by Markus Merz, CEO of a small firm focused on e-business strategies for the automotive industry (Raasch et al. 2009). 


\section{Appendix 3. Empirical data to support the deviations of WR from OSS}

\section{Marginal costs $>0$}

Manufacturing: The unit cost of WR switch and nodes is estimated by one supplier in the WR community $(\mathrm{CH} 1)$ around $\mathbf{3 . 5 0 0}$ euros.

Distribution: Distribution costs vary according to geographic distance from main suppliers (Spain, Poland, United States, Netherlands, China) and how supply is organized by each of the suppliers.

Development process: During the R\&D phase of WR, developers (users) purchased prototypes to the industrial partners (suppliers) to keep developing WR, fixing bugs and testing the technology. There are different types of bugs, according to the WR development participants:

1. Errors that could only be found by studying the designs.

2. Errors that could be found by any user; the user could find a solution because all design information is available.

3. Errors that could be found by any user, and were just reported to the other WR participants in the open so that others could solve it.

From 2009, when the project started, until 2013, 77 WR switch 18 ports were manufactured and distributed by one of the two single suppliers of WR in that period (Bij et al. 2013) (see Table 6).

\begin{tabular}{|l|l|l|l|}
\hline \multicolumn{5}{|c|}{$\begin{array}{c}\text { Table 6. Eight CERN Open Hardware designs found producers and users } \\
\text { (Sept. 2013) (Bij et al. 2013) }\end{array}$} \\
\hline Project & Producers & Users & Produced \\
\hline SPEC carrier- PCle & 3 & 41 & 300 \\
\hline SVEC carrier- VME & 2 & 4 & 105 \\
\hline SPEXI carrier- PXle & 1 & 2 & (proto) 3 \\
\hline
\end{tabular}




\begin{tabular}{|l|l|l|l|}
\hline FMC ADC 100M 14b 4ch & 2 & 11 & 70 \\
\hline FMC TDC 1ns 5cha & 1 & 3 & 70 \\
\hline FMC DEL 1ns 4cha & 3 & 4 & 108 \\
\hline FMC DIO 5ch & 3 & 10 & 92 \\
\hline WR switch 18 ports & $\mathbf{1}$ & $\mathbf{1 1}$ & $\mathbf{7 7}$ \\
\hline
\end{tabular}

\section{Investments by users of that software versus investments by users and suppliers}

Users need industrial partners - the suppliers - to manufacture and distribute the physical artifact during the process of R\&D. Such suppliers are not the final users; those are going to be their future clients. Table 7 lists all organizations that contributed to the percentages of contributions to WR development, according to the repository analysis carried by CERN.

Table 7. Contributions in WR development by Organizations (by CERN)

\begin{tabular}{|c|c|c|c|c|c|}
\hline $\begin{array}{l}\text { Repositories } \\
\text { (git name) }\end{array}$ & $\begin{array}{l}\text { Number of } \\
\text { contributions }\end{array}$ & $\begin{array}{l}\text { Number } \\
\text { of } \\
\text { commits }\end{array}$ & $\begin{array}{l}\text { Organizations } \\
\text { (country code) }\end{array}$ & $\begin{array}{l}\text { Type of } \\
\text { Organization }\end{array}$ & $\begin{array}{l}\% \text { of total } \\
\text { contributions } \\
\text { (rounded) }\end{array}$ \\
\hline \multirow{5}{*}{$\begin{array}{l}\text { White Rabbit } \\
\text { cores }\end{array}$} & \multirow[t]{5}{*}{21} & \multirow[t]{5}{*}{1353} & CERN (CH) & User & $63 \%$ \\
\hline & & & GSI (DE) & User & $26 \%$ \\
\hline & & & Elproma (PL) & Provider & $7 \%$ \\
\hline & & & Nikhef (NL) & & $3 \%$ \\
\hline & & & UGR (ES) & & $1 \%$ \\
\hline \multirow{6}{*}{$\begin{array}{l}\text { White Rabbit } \\
\text { software }\end{array}$} & \multirow[t]{6}{*}{22} & \multirow[t]{6}{*}{1488} & CERN (CH) & User & $45 \%$ \\
\hline & & & GNUDD (IT) & Provider & $38 \%$ \\
\hline & & & Elproma (PL) & Provider & $6 \%$ \\
\hline & & & GSI (DE) & User & $5 \%$ \\
\hline & & & UGR (ES) & & $0,3 \%$ \\
\hline & & & $\begin{array}{l}\text { Seven Solutions } \\
\text { (ES) }\end{array}$ & Provider & $0,2 \%$ \\
\hline \multirow{4}{*}{$\begin{array}{l}\text { White Rabbit } \\
\text { network } \\
\text { interface }\end{array}$} & \multirow[t]{4}{*}{9} & \multirow[t]{4}{*}{124} & $\begin{array}{l}\text { Seven Solutions } \\
\text { (ES) }\end{array}$ & Provider & $38 \%$ \\
\hline & & & CERN (CH) & User & $22 \%$ \\
\hline & & & Elproma (PL) & Provider & $18 \%$ \\
\hline & & & UGR (ES) & & $22 \%$ \\
\hline \multirow{2}{*}{$\begin{array}{l}\text { White Rabbit } \\
\text { switch } \\
\text { gateware }\end{array}$} & 7 & 794 & CERN (CH) & User & $99 \%$ \\
\hline & & & $\begin{array}{l}\text { Seven Solutions } \\
\text { (ES) }\end{array}$ & Provider & $1 \%$ \\
\hline \multirow{2}{*}{$\begin{array}{l}\text { White Rabbit } \\
\text { switch } \\
\text { hardware }\end{array}$} & 6 & 358 & $\begin{array}{l}\text { Seven Solutions } \\
\text { (ES) }\end{array}$ & Provider & $99 \%$ \\
\hline & & & Creotech & Provider & $1 \%$ \\
\hline \multirow{7}{*}{$\begin{array}{l}\text { White Rabbit } \\
\text { switch software }\end{array}$} & 18 & 2312 & CERN (CH) & User & $49 \%$ \\
\hline & & & GNUDD (IT) & Provider & $39 \%$ \\
\hline & & & $\begin{array}{l}\text { Seven Solutions } \\
\text { (ES) }\end{array}$ & Provider & $8 \%$ \\
\hline & & & UGR (ES) & & $4 \%$ \\
\hline & & & UTwente (NL) & User & $0,4 \%$ \\
\hline & & & Integrasys (ES) & Provider & $0,1 \%$ \\
\hline & & & GSI (DE) & User & $0,09 \%$ \\
\hline
\end{tabular}




\section{Voluntarily engagement versus active recruiting}

As Figure 7 and Table 7 show, developers were contributing to WR development, not in their spare time but mostly as part of their work in the organizations where they were employed. The majority of contributions were made in working hours (during the day) and from Monday through Friday. Furthermore, as RSE4 explains, CERN had to actively recruit companies to agree to engage in WR development. To do so, different strategies were followed and different degrees of engagement in WR development were required. As Bij et al. (2013, p.5) revealed: "To guarantee that the projects could easily find their way to other users without being dependent on CERN, engineering companies were asked to not only produce the hardware for CERN but also to add them to their product catalog. To assure quality CERN closely followed the production. By April 2013 sixteen companies have been involved in the development, production, and sales of over ten open hardware and related open software projects. These same companies also support the designs, allowing the scaling of the number of users."

Figure 7. Number of contributions (commits) to WR development/hour of a week (by CERN)

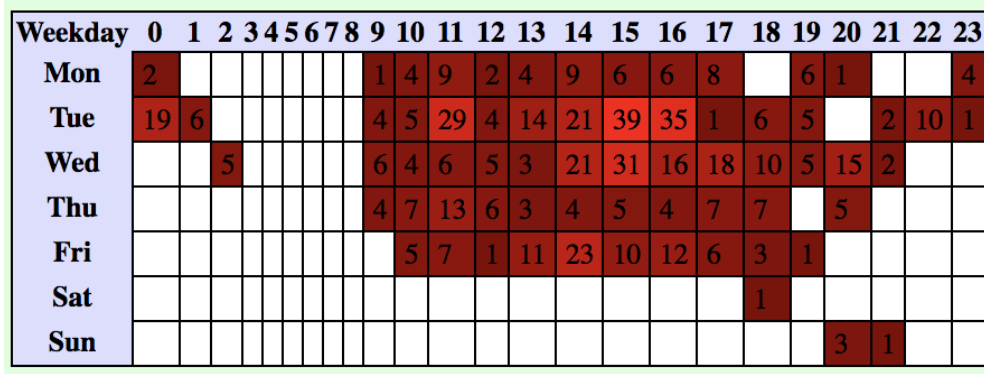

\section{4. $R \& D$ investment and the magnitude of risks if effective recruiting fails}

Cost of R\&D development of WR by one supplier, who contributed to WR development in around $45 \%$, estimated its aggregated $R \& D$ costs as Table 8 presents: 


\begin{tabular}{|l|l|l|l|l|l|}
\hline \multicolumn{7}{|c|}{ Table 8. Estimation of R\&D costs for WR development by one supplier } \\
\hline & $\begin{array}{l}\text { Person / } \\
\text { Year }\end{array}$ & $\begin{array}{l}\text { Average Cost } \\
\text { Person / Year }\end{array}$ & N years & $\begin{array}{l}\text { Total Person / } \\
\text { Years }\end{array}$ & Total \\
\hline Private investment & 2.5 & $€ 50.000$ & 9 & 22,5 & 1.125 .000 \\
\hline $\begin{array}{l}\text { Subsidy for the initial } \\
\text { period }\end{array}$ & & & & & 350.000 \\
\hline
\end{tabular}




\section{ESADE}

Ramon Llull University

Campus Barcelona · Pedralbes

Av. Pedralbes, 60-62

08034 Barcelona (España)

T. +34 932806162

F. +34 932048105

Campus Barcelona · Sant Cugat

Av. de la Torreblanca, 59

08172 Sant Cugat del Vallés

Barcelona (España)

T. +34 932806162

F. +34 932048105

\section{Campus Madrid}

Mateo Inurria, 25-27

28036 Madrid (España)

T. +34 913597714

F. +34 917030062

www.esade.edu 